NBER WORKING PAPER SERIES

\title{
RISKS FOR THE LONG RUN: A POTENTIAL RESOLUTION OF ASSET PRICING PUZZLES
}

\author{
Ravi Bansal \\ Amir Yaron \\ Working Paper 8059 \\ http://www.nber.org/papers/w8059 \\ NATIONAL BUREAU OF ECONOMIC RESEARCH \\ 1050 Massachusetts Avenue \\ Cambridge, MA 02138 \\ December 2000
}

We thank Andy Abel for detailed comments and Tim Bollerslev, John Campbell, John Cochrane, John Heaton, Lars Hansen, George Tauchen and seminar participants at Duke Economics Lunch, Indiana University, NBER Summer Institute, and Wharton Macro Lunch for helpful discussions. All errors are our own. This work has benefited from the financial support of the NSF, CIBER at Fuqua, and The Rodney White Center at Wharton. The views expressed herein are those of the authors and not necessarily those of the National Bureau of Economic Research.

(C) 2000 by Ravi Bansal and Amir Yaron. All rights reserved. Short sections of text, not to exceed two paragraphs, may be quoted without explicit permission provided that full credit, including $\subset$ notice, is given to the source. 
Risks for the Long Run: A Potential Resolution of Asset Pricing Puzzles

Ravi Bansal and Amir Yaron

NBER Working Paper No. 8059

December 2000

JEL No. G12

\begin{abstract}
We model dividend and consumption growth rates as containing a small long-run predictable component and economic uncertainty (i.e., growth rate volatility) as being time-varying. The magnitudes of the predictable variation and changing volatility in growth rates, as in the data, are quite small. These growth rate dynamics, for which we provide empirical support, in conjunction with plausible parameter configurations of the Epstein and Zin (1989) preferences can explain key observed asset markets phenomena. In particular, we show that the model can justify the observed equity premium, the low risk free rate, and the ex-post volatilities of the market return, real risk free rate, and the price-dividend ratio. As in the data, the model also implies that dividend yields predict returns and that market return volatility is stochastic. The main economic insight we capture is that news about growth rates significantly alter agent's perceptions regarding long run expected growth rates and growth rate uncertainty--in equilibrium, this leads to a large equity risk premium, low risk free interest rate, and large market volatility.
\end{abstract}

Ravi Bansal

Fuqua School of Business

Duke University

Durham, NC 27706

rb7@mail.duke.edu

\author{
Amir Yaron \\ The Wharton School \\ University of Pennsylvania \\ 2256 Steinberg-Dietrich Hall \\ Philadelphia, PA 19104 \\ and NBER \\ yaron@wharton.upenn.edu
}




\section{Introduction}

An enduring theme in economics is that asset prices are determined as an appropriately discounted value of the cashflows. Further, in equilibrium the ex-ante rates of return are determined by the preferences of the agents and the time-series properties of the cash-flows. It is well recognized by now that a wide range of general equilibrium models find it difficult to simultaneously justify key observed features of asset markets data. Shiller (1981) and LeRoy and Porter (1981) argue that the observed dividend series is too smooth to justify the observed volatility of the market return (approximately 19\% standard deviation per-annum). Mehra and Prescott (1985), Weil (1989), and Hansen and Jagannathan (1991), document the serious difficulties that standard economic models have in explaining the relatively large equity premium, and the low real risk free rate (approximately $6.5 \%$ and $1 \%$ respectively). These results suggest that from the perspective of a representative investor, with reasonably calibrated CRRA preferences, the systematic risks embodied in aggregate dividends time series are too small to justify the large equity premium. In addition, it is hard to justify the relatively high volatility of the market return and the standard empirical finding that market risk premia seem to vary across the business cycle. In this paper we present a general equilibrium model where the interaction between dividend growth rates and non-expected utility preferences (as in Epstein and Zin (1989) and Weil (1989)) reproduces all these asset markets phenomena.

It is quite standard in the asset pricing literature to model dividends (the fundamental cashflows in most asset pricing models) as a unit root process or some stationary stochastic process around a deterministic trend. The resulting model for growth rates, typically, has the feature that news regarding cashflows alter investors perceptions regarding expected growth rates only for very short horizons, if any at all. With standard preferences (as in Mehra and Prescott (1985)), it is not too surprising that investors view such cash flows as relatively riskless and, therefore, demand small risk-premia for holding it. In this paper we propose to model uncertainty in cash flow dynamics by decomposing cash-flows into cyclical and stochastic trend components. This characterization of the data, for which we provide empirical support, implies that cash-flow news should significantly alter the perceptions of agents regarding expected growth rates for the long run. The typical size of cashflow news (i.e., its volatility) is quite small, and its impact on expected growth rates even smaller. However, the fact that such news has a long lasting impact on expected growth rates makes the capitalized value of the cash-flow quite risky, and one that warrants a large risk premium.

Along with our specification for the dividend (consumption) dynamics we also need the Epstein and Zin (1989) preferences to accommodate separation between risk aversion and 
the elasticity of substitution parameters. In the absence of separation between risk aversion and the elasticity of intertemporal substitution, as is the case in time separable expected utility, there is an important tension between matching the equity premium, the risk-free rate, and the volatility of stock returns. In particular, with risk aversion greater than one, the standard model implies the counter-intuitive feature that a positive innovation to expected growth rate in cash flows implies a reduction in the price of the stock relative to current dividend. If risk aversion is smaller than one, then the equity market volatility and the risk premium may potentially be too low. Hence, the Epstein and Zin (1989)-Weil (1989) specification is important to our model just as our departure point for the cash-flow process.

In the simplest version of our model, the growth rate process for dividends is modeled and estimated in the time-series as an $\operatorname{ARMA}(1,1)$ with homoskedastic Gaussian innovations. This specification for growth rates accommodates the possibility that there is a small predictable component in growth rates. We show that the $\operatorname{ARMA}(1,1)$ specification for growth rates can be motivated as an outcome of a simple stochastic trend and cyclical variation model for the level of the dividends. Note that the risk premia on all assets with homoskedastic growth rate innovations are constant and do not vary. To allow for timevarying risk premium, we augment the above model by incorporating conditional volatility in the dividend-consumption growth rate process. This captures the economic idea that uncertainty regarding growth rates varies across the business cycle. The conditional volatility of the growth rate process is assumed to follow a simple $\operatorname{GARCH}(1,1)$ as in Bollerslev (1986). We find considerable support for a $\operatorname{GARCH}(1,1)$ volatility process for dividend growth rates.

Given the augmented growth rate process, the Epstein and Zin (1989) preferences, and the Campbell and Shiller (1988) log-linearization for continuous ex-post returns, we solve (analytically) for equilibrium asset prices. These solutions make it possible to express the model's implications for risk premia and volatility of asset returns explicitly in terms of the preference and growth rate parameters. We use these implications for the risk premia and asset return volatility to jointly estimate the preference and growth rate parameters. We find that our estimates of the preference and growth rate parameters lie in a plausible range.

Based on the estimated parameter values for preferences and the growth rate process, we find that the model can produce the observed level of the risk-free rate, the equity premium, the volatilities of stock returns, dividend-yield, and the risk free rate. In addition, the model also justifies the common empirical finding that a rise in the price-dividend ratio predicts a fall in the market risk premium. The ex-post market return in our model is stochastic and the market return volatility also follows a $\operatorname{GARCH}(1,1)$ process - this is consistent with the evidence provided in a voluminous literature on market return volatility (see for example, Bollerslev, Engle, and Wooldridge (1988)). We also show that the simpler version of the 
model where growth rate innovations are homoskedastic can also justify many of the above mentioned asset pricing the anomalies. ${ }^{1}$ Incorporating the effects of changing uncertainty in growth rates relative to the homoskedastic case increases the equity premium and the market volatility by about $20 \%$. Consequently, incorporating time varying volatility of growth rates in an empirically plausible manner, helps the model justify the asset market phenomena at lower levels of risk aversion and elasticity of substitution parameters. Our results suggest that the market compensation for changing economic uncertainty risk is about $1.2 \%$ per annum.

There is voluminous literature that addresses the aforementioned asset market anomalies. Notable examples, Abel (1990), Abel (1999), Bansal and Coleman (1997), Campbell (1996), Campbell and Cochrane (1999), Cecchetti, Lam, and Mark (1990), Constantinides (1990), Constantinides and Duffie (1996), Hansen, Sargent, and Tallarini (1999), Heaton (1995), Heaton and Lucas (1996), Kandel and Stambaugh (1991), address various aspects of the asset market anomalies discussed above. The approaches taken to address these asset market phenomena include transaction costs, incomplete markets, and time-non-separable preferences. Note that in the context of frictionless markets, variation in price-dividend ratios can come about either due to variation in expected growth rates of dividends or variations in ex-ante rates of return (discount rates). Indeed a recurring theme in this literature is to ascribe much of the variation in price-dividend ratios to variation in discount rates, where it is commonly assumed that dividend growth rates are i.i.d. However, in our model the main source of the variability in the price-dividend ratios is variation in expected growth rates. Indeed, we explain many of the aforementioned asset market puzzles with very little variation in discount rates.

It is natural and perhaps important to ask, what additional evidence, particularly at the micro level, supports our contention that dividend growth rates have components with significant long run implications. We feel there is considerable micro-level evidence to support this view, for example, Easton and Zmijewski (1989) and Kormendi and Lipe (1987) show that news about earnings have significant impact on returns and valuation ratios. At an aggregate level, Barsky and DeLong (1993) argue that the price elasticity of the market index with respect to dividends is significantly bigger than one - implying that the market price of equity changes significantly in response to changes in aggregate dividends. This impact of fundamental news on asset prices is consistent with our model, where such news significantly alter perceptions about long-term growth rates and hence valuation ratios.

The paper is organized as follows. Section 2 presents our model. In section 3 we present a closed form solution for asset prices. Section 4 presents our estimation results and discusses

\footnotetext{
${ }^{1}$ Also, see Bansal and Yaron (2000) for explicit empirical tests of this restricted version.
} 
the empirical evidence. Section 5 contains some concluding remarks.

\section{An Economic Model for Asset Markets}

Consider a representative agent with the following Epstein and Zin (1989) - Weil (1989) recursive preferences:

$$
U_{t}=\left\{(1-\delta) C_{t}^{\frac{1-\gamma}{\theta}}+\delta\left(E_{t}\left[U_{t+1}^{1-\gamma}\right]\right)^{1 / \theta}\right\}^{\frac{\theta}{1-\gamma}}
$$

where $0<\delta<1$ and $\delta^{-1}-1$ is the rate of time preference. Let $\theta \equiv \frac{1-\gamma}{1-\frac{1}{\psi}}$, where $\gamma \geq 0$ is the risk-aversion (sensitivity) parameter, and $\psi \geq 0$ is the intertemporal elasticity of substitution. The sign of $\theta$ is determined by the magnitudes of the risk-aversion and the elasticity of substitution. In particular if $\psi>1$ and $\gamma>1$ then $\theta$ will be negative. Note that when $\theta=1$, that is $\gamma=(1 / \psi)$, the above recursive preferences collapse to the standard case of expected utility, with $U_{t}^{1-\gamma}=(1-\delta) \sum_{j=0}^{\infty} \delta^{j} C_{t+j}^{1-\gamma}$. Further, when $\theta=1$ and in addition $\gamma=1$, we get the standard case of $\log$ utility.

The above representative agent maximizes life-time utility subject to the period budget constraint

$$
C_{t}+P_{t}^{\prime} \vartheta_{t+1}=d_{t}^{\prime} \vartheta_{t}+P_{t}^{\prime} \vartheta_{t} \equiv W_{t}
$$

$P_{t}^{\prime}$ refers to the vector of asset price per share at date $t$ that offers a real dividend stream of $d_{t+j}^{\prime}, j=1, \cdots \infty$. $\vartheta_{t}$ is vector of asset holdings at the end of time-period $t-1$ (note that this vector also includes the payoff 1 from the risk-free asset). Given the above information note that at date $t$ the wealth of the agent is $W_{t}$. The above budget constraint can also be written as

$$
\left(W_{t}-C_{t}\right) * R_{a, t+1}=W_{t+1}
$$

where $W_{t}-C_{t}=P_{t}^{\prime} \vartheta_{t+1}$, equals the amount of capital invested in the asset markets, and $R_{a, t+1}=\frac{P_{t+1}^{\prime} \vartheta_{t+1}+d_{t+1}^{\prime} \vartheta_{t+1}}{P_{t}^{\prime} \vartheta_{t+1}}=\frac{W_{t+1}}{\left(W_{t}-C_{t}\right)}$ is the return on portfolio held by the agent. As in Lucas (1978), we normalize the supply of all equity claims to be one and the risk-free asset to be in zero net supply. In equilibrium, aggregate dividends in the economy, defined as $D_{t}$, equal aggregate consumption of the representative agent. That is $d_{t}^{\prime} \vartheta^{*}=D_{t}=C_{t}$, where the vector, $\vartheta^{*}$, the aggregate supply of assets, has ones everywhere except for the entry corresponding to the risk free rate which is zero.

For this economy, Epstein and Zin (1989) show, that the asset pricing restrictions for asset return $R_{i, t+1}$ satisfy,

$$
E_{t}\left[\delta^{\theta} G_{t+1}^{-\frac{\theta}{\psi}}\left(1+R_{a, t+1}\right)^{-(1-\theta)}\left(1+R_{i, t+1}\right)\right]=1
$$


where $G_{t+1}$ is the aggregate gross growth rate of consumption. It follows that for the return on the aggregate consumption portfolio, $R_{a, t+1}$,

$$
E_{t}\left[\delta^{\theta} G_{t+1}^{-\frac{\theta}{\psi}}\left(1+R_{a, t+1}\right)^{\theta}\right]=1
$$

From the definition of a return, it follows that

$$
1+R_{a, t+1}=\frac{\left(1+P_{a, t+1} / C_{t+1}\right)}{P_{a, t} / C_{t}}\left(C_{t+1} / C_{t}\right)
$$

where we refer to $\left(P_{a, t} / C_{t}\right)$ as $Z_{t}$. An equilibrium for this economy is a solution for $Z_{t}$ that solves the functional equation (2). Further note that as consumption equals dividends, $R_{a, t+1}$, the return on the aggregate consumption process, also coincides with the return on aggregate dividends - that is, the market portfolio. In section 3.2 we make an explicit distinction between the consumption and dividend processes.

Continuous versions of variables needed to characterize the solution for the model are written in lower case letters; hence, $\ln \left(1+R_{a, t+1}\right) \equiv r_{a, t+1}, \ln \left(G_{t+1}\right) \equiv g_{t+1}$, and $\ln \left(Z_{t}\right)=z_{t}$. Note that (2) can be written in terms of the continuous variables as,

$$
E_{t}\left[\exp ^{\left\{\theta \ln (\delta)-\frac{\theta}{\psi} g_{t+1}+\theta r_{a, t+1}\right\}}\right]=1
$$

The continuous return can be written as $r_{a, t+1}=\ln \left(1+\left(P_{a, t+1} / C_{t+1}\right)\right)-z_{t}+g_{t+1}$. To derive analytical solution to the model we use the standard approximation derived in Campbell and Shiller (1988), and Campbell (1993),

$$
r_{a, t+1}=\kappa_{0}+\kappa_{1} z_{t+1}-z_{t}+g_{t+1}
$$

where $\kappa_{0}$ and $\kappa_{1}$ are approximating constants and both depend only on the average level of $z^{2}$

Note that the inter-temporal marginal rate of substitution, or the "pricing kernel" in this model is $M_{t+1}=\delta^{\theta} G_{t+1}^{-\frac{\theta}{\psi}}\left(1+R_{a, t+1}\right)^{-(1-\theta)}$. The one step ahead innovation, in $\log \left(M_{t+1}\right)$, is

$$
\eta_{M, t+1}=-\frac{\theta}{\psi} \eta_{t+1}-(1-\theta) \eta_{a, t+1}
$$

where $\eta_{t+1}$ is the innovation in continuous growth rate of consumption and $\eta_{a, t+1}$ is the

\footnotetext{
${ }^{2}$ Note that $\kappa_{1}=\exp (\bar{z}) /(1+\exp (\bar{z}))$. In our empirical work $\kappa_{1}=0.9969$, which is based on the magnitude of $\bar{z}$ in our sample. This is consistent with magnitudes used in Campbell and Shiller (1988). Further note that Campbell and Koo (1997) show that the solution to their model is not very sensitive to this approximation.
} 
innovation in the continuous market return.

\subsection{Growth Rate Process}

To solve the model we first need to characterize the growth rate process. The growth rate process can potentially have large effects on the implied volatility of the equity return and the size of the equity premium. For convenience, it will be easier for us, at this stage, to capture the idea of stochastic trends and cyclical variation in dividends by characterizing the growth rate process as an $\operatorname{ARMA}(1,1)$ process. As shown later, this process for growth rates can be motivated by assuming that the stochastic trend for the level of dividends follows an exponential smoothing process and the cyclical component is a standard first order auto-regressive process. We subsequently show empirically that the $\operatorname{ARMA}(1,1)$ is a good description of the dividend growth rate. For simplicity, for now, we equate the dividends and consumption processes and subsequently provide a model that treats them as separate processes.

$$
g_{t}=\mu+\rho g_{t-1}+\eta_{t}-\omega \eta_{t-1}
$$

Note that this process can be more conveniently written as

$$
g_{t}=\frac{\mu}{(1-\omega)}+(\rho-\omega) \frac{g_{t-1}}{1-\omega L}+\eta_{t}
$$

where $L$ is the lag operator. It is assumed that $g$ is stationary, and hence $\rho$ and $\omega$ are less than one in absolute value. While this standard $\operatorname{ARMA}(1,1)$ process characterizes the dynamics for the growth rate, the relevant state variable that affects the present values of cash flows is the conditional mean of this process. The conditional mean of $g_{t}$ at date $t-1$ is determined by the state variable $x_{t-1}$, where

$$
x_{t-1}=\frac{\mu}{(1-\omega)}+(\rho-\omega) \frac{g_{t-1}}{1-\omega L}
$$

Using (8) and (9), it follows that $x_{t}$ is an $\mathrm{AR}(1)$ process,

$$
x_{t}=\mu+\rho x_{t-1}+(\rho-\omega) \eta_{t}
$$

The parameter $\rho$ determines the persistence of the process, and $\omega$ is the smoothing parameter that affects the construction of $x_{t}$. There are two cases of particular interest that the $\operatorname{ARMA}(1,1)$ representation accommodates. If $\rho=\omega$, then the conditional mean of $g$ is 
a constant, and $g$ is an i.i.d process. Second, if $\omega=0$, then $g$ is a standard $\operatorname{AR}(1)$ process. Consider the revision in expected growth rates for horizon $n \geq 1$

$$
E_{t}\left[g_{t+n}\right]-E_{t-1}\left[E_{t}\left(g_{t+n}\right)\right]=\rho^{n-1}(\rho-\omega) \eta_{t}
$$

Equation (11) shows that if $\rho-\omega \neq 0$, then rational agents will revise their long-run expected growth rates in the amount stated in (11). If $\rho-\omega$ is positive and small then the revision in long-run expected growth rates is quite small; in the extreme case when $\rho=\omega$ there is no revision in the expected growth rate at all. The "permanence" of the expectation revision is determined by $\rho$ - if it happens to equal one, then the revision in expectation is identical across all horizons. When $\rho$ is less than one, the revision is larger for shorter horizons and almost zero for very long horizons. An interesting case is where the difference between $\rho$ and $\omega$ is small and positive, and $\rho$ is large - in this case growth rate news leads to very small revisions to the long-run expected growth rate.

It is important to note that when $\rho$ is even slightly bigger than $\omega$ the growth rate process will look very close to an i.i.d process - the asset pricing implications, however, can dramatically differ from the case in which the growth rate is assumed to be i.i.d (that is, $\rho$ exactly equals $\omega$ ). It is quite likely, that in finite samples, the data on dividend (or consumption) growth rate by itself may not sharply be able to distinguish across these different cases. $^{3}$ It would then seem that the different asset pricing implications of these alternative growth rate specifications may prove to be valuable in sharper identification of the growth rate process itself. In a similar vein Cochrane and Hansen (1992) argue that asset markets data provide important information regarding preference parameters.

Barsky and DeLong (1993) use the classic Gordon Growth Formula and an expected growth rate process with a unit root (equation (10) with $\rho=1$ ) to document that such a specification can explain fluctuations in the market index. Bansal and Lundblad (1999) consider the $\operatorname{ARMA}(1,1)$ specification for dividend growth rates (see equation (7)) in an international context and explore its implications for asset return cross-correlations across economies utilizing the market return based static-CAPM model.

To allow for time variation in risk premia, we further assume that there is stochastic volatility in the growth rate dynamics - where, $\sigma_{g, t}^{2}$ is the stochastic volatility of the growth rate. Following Bollerslev (1986) we model the stochastic volatility process as a GARCH $(1,1)$.

\footnotetext{
${ }^{3}$ Shephard and Harvey (1990) provide small sample evidence which shows that with population values of $\rho=1$, and $1-\omega$ small ( $\omega$ around .9), standard estimation procedures, in finite samples, are biased toward estimating values of $\omega$ equal to one. This suggests that it is difficult, in finite samples, to detect permanent components. We suspect that the same problems are endemic to our case when $\rho$ is moderately less than one, and $\rho-\omega$ is small.
} 
That is, the squared innovations in the growth rate, $\eta_{t+1}^{2}$ follows an $\operatorname{ARMA}(1,1)$ process,

$$
\begin{aligned}
\eta_{t+1}^{2} & =\nu_{0}+\nu_{1} \eta_{t}^{2}+e_{t+1}-\omega_{v} e_{t}, \\
\sigma_{g, t+1}^{2} & =\nu_{0}+\nu_{1} \sigma_{g, t}^{2}+w_{t+1}
\end{aligned}
$$

where $\sigma_{g, t}^{2} \equiv E_{t}\left[\eta_{t+1}^{2}\right]$, and $w_{t+1} \equiv\left(\nu_{1}-\omega_{v}\right)\left(\eta_{t+1}^{2}-\sigma_{g, t}^{2}\right)=\left(\nu_{1}-\omega_{v}\right) e_{t+1} \cdot{ }^{4}$ Further, we assume that $w_{t}$ is normally distributed and is independent of the innovation in consumption growth rate $\eta_{t} .^{5}$

\section{Solving for Asset Prices}

\subsection{Solution}

As stated earlier to solve the model we need to derive the process for $z_{t} \equiv \log \left(P_{a, t} / D_{t}\right)$. The relevant state variables for deriving the solution, in the absence of asset bubbles, are $x_{t}$ and $\sigma_{g, t^{*}}^{2}$. To derive a solution for the endogenous variable $z_{t}$, we substitute (5) for $r_{a, t+1}$ in (4). To do so we conjecture that $z_{t}=A_{0}+A_{1} x_{t}+A_{2} \sigma_{g, t}^{2}$. This conjecture, along with Euler equation associated with the market return, (4), are used to solve for the unknown vector of coefficients $\mathbf{A}=\left[A_{0}, A_{1}, A_{2}\right]$, using the procedure discussed in McCallum (1983). The details for the solution for these coefficients are provided in Appendix A - section 6.1.

The solution coefficient for $A_{1}$ is,

$$
A_{1}=\frac{1-\frac{1}{\psi}}{1-\kappa_{1} \rho}
$$

Note that an a-priori belief that higher expected growth in dividends raises the price-dividend ratio, would imply that $A_{1}$ is positive. With $|\rho|<1$ one would require $\psi$ to be bigger than one to ensure that $A_{1}$ is positive. The positivity of $A_{1}$ captures the usual intuition of the textbook Gordon Growth formula that higher expected growth, all else equal, should increase the valuation. Note that if $|\rho|<1$ then the standard expected utility model, with risk aversion bigger than one (i.e., $\psi<1$ ), would imply that $A_{1}$ is negative - a rise in expected growth rates leads to a fall in the price-dividend ratio.

\footnotetext{
${ }^{4}$ Equation (12) can be derived as follows, $\eta_{t+1}^{2}=\nu_{0}+\nu_{1} \eta_{t}^{2}+e_{t+1}-\omega_{v} e_{t}$ or $\eta_{t+1}^{2}=\frac{\nu_{0}}{1-\omega_{v}}+\left(\nu_{1}-\omega_{v}\right) \frac{\eta_{t}^{2}}{1-\omega_{v} L}+$ $e_{t+1}$. Note that $\sigma_{g, t}^{2} \equiv E_{t}\left[\eta_{t+1}^{2}\right]=\frac{\nu_{0}}{1-\omega_{v}}+\left(\nu_{1}-\omega_{v}\right) \frac{\eta_{t}^{2}}{1-\omega_{v} L}$, which in turn implies $\sigma_{g, t}^{2}=\nu_{0}+\nu_{1} \sigma_{g, t-1}^{2}+w_{t}$.

${ }^{5}$ For simplicity we will let $w_{t}$ be a mean zero normal, however, one can assume some other distribution such a chi-square with one degree of freedom, this will not change the main results. The main assumption required is that the innovation in stochastic volatility process is homoskedastic, without this simplifying assumption, the solution to the model losses it simplicity, and may not be solvable analytically.
} 
The solution coefficient for for $A_{2}$ is

$$
A_{2}=\frac{0.5\left[\theta-\frac{\theta}{\psi}+\theta A_{1} \kappa_{1}(\rho-\omega)\right]^{2}}{\theta\left(1-\kappa_{1} \nu_{1}\right)}
$$

Note that if $\theta$ is negative, then the effect of a rise in volatility is to lower the price to dividend ratio. Note that if $\psi>1$, then $\theta<0$ for risk aversions that are bigger than one. Hence, in the case when risk aversion is bigger than one, a rise in uncertainty would lead to a drop in the price-dividend ratios. An a priori belief that increased economic uncertainty should lead to a drop in asset prices suggest that if $\gamma>1$, then $\psi>1$ as well.

\subsubsection{The Equity Premium}

Given the solutions for A, it is straightforward to derive (shown in section 6.1) the expression for the return on the aggregate consumption portfolio (recall that for now it coincides with the market return) from which it follows that the innovation in this return is,

$$
\eta_{a, t+1}=\left[1+\kappa_{1} A_{1}(\rho-\omega)\right] \eta_{t+1}+\kappa_{1} A_{2} w_{t+1}
$$

Further note that the conditional variance of the market return can be expressed as,

$$
\operatorname{var}_{t}\left[\eta_{a, t+1}\right] \equiv \sigma_{a, t}^{2}=\left[1+\kappa_{1} A_{1}(\rho-\omega)\right]^{2} \sigma_{g, t}^{2}+\left[\kappa_{1} A_{2}\right]^{2} \sigma_{w}^{2}
$$

Also, the conditional covariance between the consumption innovation and the market return innovation is,

$$
\operatorname{cov}_{t}\left(\eta_{t+1}, \eta_{a, t+1}\right)=\left[1+\kappa_{1} A_{1}(\rho-\omega)\right] \sigma_{g, t}^{2}
$$

If asset returns and the pricing kernel are conditionally log-normal, as is the case here, then the continuous risk premium is,

$$
E_{t}\left[r_{i, t+1}-r_{f, t}\right]=-0.5 \sigma_{r_{i}, t}^{2}-\operatorname{cov}_{t}\left(\ln \left(M_{t+1}\right), r_{i, t+1}\right)
$$

The arithmetic risk premium, $E\left[R_{i, t+1}-R_{f, t}\right]$ can be derived by adding the Jensen's effect piece, $0.5 \sigma_{r_{i}, t}^{2}$, to both sides of the above expression. The risk premium on the market portfolio, the derivation of which is provided in equation (6.1) in Appendix A, is,

$$
E_{t}\left[R_{a, t+1}-R_{f, t}\right]=B\left[\frac{\theta}{\psi}+(1-\theta) B\right] \sigma_{g, t}^{2}+\kappa_{1} A_{2}\left[(1-\theta) \kappa_{1} A_{2} \sigma_{w}^{2}\right]
$$

where $B=\left[1+\kappa_{1} A_{1}(\rho-\omega)\right]$. Note that $B$ plays a critical role in the determination of 
the risk premium in equation (17). $B$, as shown later, is bigger than one, and captures the impact on long-term expected growth rates in response to innovations in dividend growth rates. The impact of this persistent component on the equity premium via $B$ can be very large - implying a large equity premium. Further note that volatility risk is priced and affects the risk premium when $\theta \neq 1$.

To provide intuition regarding the various effects on the market risk premium, consider some special cases. First, consider the case of standard time-separable preferences where $\theta=1$, or equivalently $\gamma=1 / \psi$. From (17) it is evident that the equity premium is

$$
E_{t}\left[R_{a, t+1}-R_{f, t}\right]=\gamma B \sigma_{g, t}^{2}
$$

Note that with expected utility volatility risk is not priced. With $\theta=1$, the innovation in the market return does not explicitly affect the innovation in the IMRS - see (6). This is an outcome of the fact that innovations to stochastic volatility do not affect the marginal utility of wealth with expected utility preferences. When $\rho=\omega$ and volatility is constant, that is, the dividend process is $i . i . d$ and consequently $B=1$. In this case the risk premium of the market portfolio is product of the variance of growth rates and risk aversion. Further, $\gamma=(1 / \psi)=1$ (hence $\log$ utility) ensures that $B=1$ even if $\rho \neq \omega$, and the resulting market return is exactly equal to the growth rate process. ${ }^{6}$

Next, consider the more general case where the risk aversion parameter need not equal the reciprocal of the elasticity of substitution parameter (i.e., $\theta$ need not equal 1). In this case with $\rho=\omega$ (hence $B=1$ ) the equity premium simplifies to $E_{t}\left[R_{a, t+1}-R_{f, t}\right]=$ $\gamma \sigma_{g, t}^{2}+(1-\theta)\left[\kappa_{1} A_{2}\right]^{2} \sigma_{w}^{2}{ }^{7}$ The effect of $\theta \neq 1$ is that volatility risk is priced. An interesting case is one where $\theta<0$ and $B>1$, in which case the magnification afforded by the term pre-multiplying $\sigma_{g, t}^{2}$ can be big enough to generate a large equity premium. This captures the intuition that small innovations in the growth rate lead to large changes in the market return, which in turn is positively correlated with the representative agent's consumption. To hold the market portfolio the agent needs to be compensated for bearing this risk by being offered a large equity premium.

Given the expression for the volatility of $R_{a}$ in (16), note that the geometric equity premium, the focus of our empirical analysis, is straightforward to derive,

$$
E_{t}\left[r_{a, t+1}-r_{f, t}\right]=B\left[\frac{\theta}{\psi}+(1-\theta) B\right] \sigma_{g, t}^{2}+(1-\theta)\left[\kappa_{1} A_{2}\right]^{2} \sigma_{w}^{2}-0.5 \sigma_{a, t}^{2}
$$

\footnotetext{
${ }^{6}$ Note that in the case of log-utility $A_{1}$ and $A_{2}$ are equal to zero and price dividend ratio is constant.

${ }^{7}$ This follows from recognizing that the term pre-multiplying $\sigma_{g, t}^{2}$ in (17) collapses to $\gamma$. To see this recall that $\theta$ is equal to $\frac{1-\gamma}{1-\frac{1}{\psi}}$, and with $B=1$ it follows that $\left[\frac{\theta}{\psi} B+(1-\theta) B^{2}\right]$ is equal to $\left(\frac{\theta}{\psi}+1-\theta\right)=\gamma$.
} 


\subsubsection{The Risk Free Rate and Volatility}

To derive the risk free rate we exploit the Euler condition in (4) and the fact that the pricing kernel is log-normally distributed. This allows us to derive the following expression for the risk free rate (details are given in section 6.2 of Appendix A).

$$
r_{f, t}=-\log (\delta)+\frac{1}{\psi} E_{t}\left[g_{t+1}\right]+\frac{(1-\theta)}{\theta} E_{t}\left[r_{a, t+1}-r_{t}\right]-\frac{1}{2 \theta} \operatorname{Var}_{t}\left[\frac{\theta}{\psi} g_{t+1}+(1-\theta) r_{a, t+1}\right]
$$

As is standard in most models, a rise in expected growth rates increases the risk free rate here as well. The volatility of the pricing kernel (the last term in the expression for $r_{f, t}$ ) can be fairly large if the return to the market volatility is large, which can significantly alter the implications for the level of the risk free rate. Further, if $\theta<0$ a rise in the equity premium lowers the risk free rate.

The volatility of the risk free rate is determined by the volatility of the expected growth rate process and the volatility of the conditional variance of dividend growth rate. In particular, we show that,

$$
\operatorname{Var}\left(r_{f, t}\right)=\left(\frac{1}{\psi}\right)^{2} \operatorname{Var}\left(x_{t}\right)+\left\{\frac{1-\theta}{\theta} K_{2}-B_{p k}^{2} \frac{1}{2 \theta}\right\}^{2} \operatorname{Var}\left(\sigma_{g, t}^{2}\right)
$$

where the details of derivation and the constants $B_{p k}$ and $K_{2}$ are given in section 6.2 of Appendix A. Note that in the absence of stochastic volatility in the model, the volatility of the risk free rate is determined by the volatility of $x$ and the elasticity of substitution, $\psi-$ larger values of $\psi$ lower the volatility of the risk free rate.

Finally, the volatility of the market portfolio return $r_{a}$ is,

$$
\operatorname{Var}\left(r_{a, t}\right)=B^{2} \operatorname{Var}\left(\eta_{t+1}\right)+\left(\frac{1}{\psi}\right)^{2} \operatorname{Var}\left(x_{t}\right)+\left[A_{2}\left(\kappa_{1} \nu_{1}-1\right)\right]^{2} \operatorname{Var}\left(\sigma_{g, t}^{2}\right)+\left[A_{2} \kappa_{1}\right]^{2} \sigma_{w}^{2}
$$

where again, $B \equiv\left[1+A_{1} \kappa_{1}(\rho-\omega)\right]$. The first order effect on the volatility of the market return is $B^{2}$. As discussed earlier, $B$ captures the impact of dividend innovations on longterm expected growth rates. As long as $A_{1}>0$ an increase in $\rho$, with $\rho-\omega>0$, increases $B$ implying growth innovations have bigger impact on market volatility.

\subsection{Separating Consumption and Dividends}

In this section we model consumption and dividends as separate processes. Note that in what follows our consumption growth rate process will be identical to that in (7). We augment this consumption growth rate process with one for dividends. This parsimonious bivariate 
process allows for imperfect correlation between consumption and dividend growth rates and captures the fact that dividends are more volatile than consumption.

$$
\begin{aligned}
g_{t+1} & =x_{t}+\eta_{t+1} \\
g_{d, t+1} & =\mu_{d}+\lambda x_{t}+\eta_{d, t+1} \\
\eta_{t+1} & =\sigma_{g, t} \eta_{c, t+1} \\
\eta_{d, t+1} & =\tau \lambda \sigma_{g, t} \eta_{c, t+1}+\sqrt{1-\tau^{2}} \lambda \sigma_{g, t} e_{d, t+1} \\
\eta_{c, t+1}, \eta_{d, t+1} & \sim N(0,1) \quad \text { and } \operatorname{corr}_{t}\left(\eta_{t+1}, \eta_{d, t+1}\right)=\tau
\end{aligned}
$$

where $\eta_{c, t+1}$ and $e_{d, t+1}$ are uncorrelated. Note that this framework ensures that the $g_{t+1}$ process is identical to that discussed earlier in (7), and (9). Moreover, this structure implies that the conditional variance of $\eta_{t+1}$ and $\eta_{d, t+1}$ are $\sigma_{g, t}^{2}$ and $\lambda^{2} \sigma_{g, t}^{2}$ respectively. The parameter $\lambda$ is the leverage ratio as in Abel (1999). A meaningful interpretation of $\lambda$ is that it equals the ratio of the unconditional standard deviation of the dividends and consumption growth rates. The above structure implies that the $R^{2}$ from predicting $g_{t+1}$ and $g_{d, t+1}$ given $x_{t}$ are equal. ${ }^{8}$ Further, note that $\operatorname{var}\left(\eta_{d}\right)=\lambda^{2} \operatorname{var}\left(\eta_{c}\right)$. Since, dividends are more volatile than consumption $\lambda$ will be bigger than 1 . Note that when $\tau=1$ and $\lambda=1$, the above specification collapses to the model specification discussed earlier in the paper and dividend growth rates are perfectly correlated with consumption growth rates. Finally, note that the relevant state variables for deriving asset prices are still $x_{t}$ and $\sigma_{g, t}$

To solve the model, as in the previous discussion, we first need to compute the solution to the endogenous variable, $z_{t}=\log \left(P_{a, t} / C_{t}\right)$. The solution to this variable is entirely unchanged as the consumption process and consequently the IMRS for our model are unaltered by the introduction of the auxiliary dividend process. However, to compute the market return which is a claim to the dividend process, we need to solve for $z_{m, t}=\log \left(P_{m, t} / D_{t}\right)$. The solution for $z_{m, t}$ (details of which are given in section 6.3.1 in Appendix A) is,

$$
\begin{aligned}
z_{m, t} & =A_{0, m}+A_{1, m} x_{t}+A_{2, m} \sigma_{g, t}^{2} \quad \text { where } \\
A_{1, m} & =\frac{\lambda-\frac{1}{\psi}}{1-\kappa_{1, m} \rho}=\lambda \frac{1-\frac{1}{\lambda \psi}}{1-\kappa_{1, m} \rho}
\end{aligned}
$$

The $\lambda$ appearing in $A_{1, m}$ captures the idea that dividends are levered relative to aggregate consumption. Note, that the market price to dividend ratio is likely to be more volatile than the market price for a claim on consumption, since $A_{1, m}$ is likely to be bigger than $A_{1}$. The

${ }^{8}$ Note that the $R^{2}$ for $g_{t+1}$ is simply $\left[\operatorname{var}\left(x_{t}\right) / \operatorname{var}\left(g_{t+1}\right)\right]=\operatorname{var}\left(x_{t}\right) /\left(\operatorname{var}\left(x_{t}\right)+E\left(\sigma_{g, t}^{2}\right)\right)$. Similarly the $R^{2}$ for dividend growth rate is $\lambda^{2} \operatorname{var}\left(x_{t}\right) /\left(\lambda^{2} \operatorname{var}\left(x_{t}\right)+\lambda^{2} E\left(\sigma_{g, t}^{2}\right)\right)$, which is equal to the $R^{2}$ for $g_{t+1}$. 
solution for $A_{2, m}$ can be derived (see section 6.3.1 of Appendix A) in an analogous manner to that discussed in the context of $A_{2}$. Moreover, exploiting the same solution procedures as in the previous sections one can derive analytical solutions for the equity premium, risk free rate, market return volatility, and the risk free rate volatility. The derivation for all these quantities for the above specification of the consumption-dividend model is provided in the Appendix B. The economic intuition in the context of this model is identical to that discussed in the consumption equal dividend model $(\lambda=1, \tau=1)$ in the earlier sections.

To provide some sense for what drives premiums in this setting, consider the expression for the equity premium. The return on the market portfolio is $r_{m, t+1}$,

$$
E_{t}\left(r_{m, t+1}-r_{f, t}\right)=B_{m}\left[\left(-B_{p k}\right) \sigma_{g, t}^{2}\right]+A_{2, m} \kappa_{1, m}\left[(1-\theta) A_{2} \kappa_{1} \sigma_{w}^{2}\right]-0.5 \operatorname{Var}_{t}\left(r_{m, t+1}\right)
$$

where $B_{p k}=\left[-\frac{\theta}{\psi}+(\theta-1) B\right]$ and $B_{m}$ - the beta of the asset with respect to consumption innovation risk, is $\left(\tau \lambda+\kappa_{1, m} A_{1, m}(\rho-\omega)\right)$. Note that with $\lambda=1$, and $\tau=1$ this expression is identical to equation (17) discussed above. There are two sources of systematic risk - the consumption innovation risk, and the innovation in consumption volatility. Further note that the systematic risk compensation for these two sources of risk are the expressions in the squared brackets in equation (25). The endogenously determined beta's of a given asset to these risks are the analogue of $B_{m}$ and $A_{2, m}$ respectively. In the context of the market claim, it is clear that a rise in $\lambda$ or $\tau$ raises $B_{m}$ and hence the equity premium.

\section{Empirical evidence}

\subsection{Data}

We construct a monthly series of real dividend growth rates using the CRSP data set. Specifically, dividends are imputed from the Value Weighted return on the NYSE including and excluding dividends. Using the market capitalization rate and the CPI index we construct a real valued dividend index for monthly observations from January 1927 to December 1998. The de-seasonalized level of dividend is a trailing 12 month average - this procedure is similar to that in Bollerslev and Hodrick (1995), Heaton (1995), and Hodrick (1992). For each date the monthly dividend growth rate is defined as the continuous growth rate of this de-seasonalized level of dividends.

The top panel in Table 1 provides summary statistics of the first 2 moments and first 2 autocorrelations of the data used in the paper. The table provides information on dividend growth rate, the Value Weighted return on NYSE, real return on the one-month Treasury 
Bill, and inflation. Note that the measured real risk free rate is constructed by subtracting a trailing 12-month moving average of inflation from the nominal one month T-bill rate that is subtracting an empirical proxy for expected inflation. All the return series including inflation are taken from the CRSP data set. The stylized facts discussed in the introduction are evident in Table 1 . That is the continuous mean equity premium and real risk free rate are $6.5 \%$ and $.56 \%$ respectively, per-annum. The annualized standard deviation of the market return and the real risk free rate are about $19 \%$ and $1 \%$ respectively. In our sample the volatility of the market return is particularly large.

\subsection{Cash Flow Dynamics}

In Panel A of Table 2 we provide the ARMA $(1,1)$ estimates for the dividend growth rate process. The $\operatorname{AR}(1)$ coefficient, $\rho$, is .965 and the $\mathrm{MA}(1)$ coefficient, $\omega$, is .85 . These correspond quite closely to the type of estimates discussed earlier in motivating the model. In particular, the null hypothesis of an i.i.d. growth rate process (i.e., $\rho=\omega$ ) can be rejected at conventional significance levels using the Andrews and Ploberger (1996) test. ${ }^{9}$ We also report the estimates for the $\operatorname{ARMA}(1,1)$ model with $\operatorname{GARCH}(1,1)$ stochastic volatility in the innovations of the dividend growth rate process. Note that the volatility process is quite persistent with $\nu_{1}=0.983$. The innovation in stochastic volatility, determined by the difference $\nu_{1}-\omega_{v}=0.032$, is quite small. The economic implications of these estimates for the conditional mean of the growth rate process are: first, that it is quite persistent, and second, that the optimal forecast of the conditional mean is revised in the amount of $0.965-0.85=0.114$ in the direction of the innovation in the growth rate. Analogously, the volatility forecasts are revised approximately in the amount of $\nu_{1}-\omega_{v}$. Further, note that the estimates above imply that the predictable variation (adjusted $R^{2}$ ) in the $\operatorname{ARMA}(1,1)$ and its stochastic volatility process are about $14 \%$ and $2 \%$ respectively - indicating these processes contain a small predictable component.

An often held view is that the log-levels of consumption and dividends are a random walk with a drift. Another commonly held view, seen extensively in the RBC literature (e.g., Kydland and Prescott (1982)), is that aggregate time-series can be meaningfully decomposed into a trend and business-cyclical components by a filter such as the HP-filter. Not surprisingly, the asset pricing implications will be significantly different across these two alternative characterization of the data. It is not clear, however, that the time series

\footnotetext{
${ }^{9}$ Andrews and Ploberger (1996) provide a formal test for the hypothesis that $\rho=\omega$. The test of this hypothesis is non-standard since under the null that $\rho=\omega$ the AR and MA parameters of the ARMA $(1,1)$ are separately identified only under the alternative. They construct a likelihood ratio test (based on the quantity $\left.\sup _{\omega} L R_{T}(\omega)\right)$ and provide the non-standard asymptotic distribution for this test statistic.
} 
dynamics of consumption and dividends, in themselves, can speak to which of these two views is the correct one.

For example, in Panel B of Table 2 we decompose, using the HP-filter, the monthly dividend growth rate series into cyclical and stochastic trend components. In utilizing the HP filter we used the 'standard' RBC "smoothing" parameter of $\lambda=14400$ (see Hodrick and Prescott (1997) for details). The first two columns in Panel B provide the first two autocorrelations of the growth rate of the trend and cyclical components. The results indicate that the trend growth rate component is very persistent while the growth in the cyclical component is not very persistent. The last column, denoted Var-Ratio reports the relative variance of each component to the overall growth rate variance. The results in that panel suggest that the growth rate in the "Trend" component is small in size but very persistent, whereas the growth rate of the cyclical component is quite volatile but not persistent. Viewed from the perspective of the HP filter, it seems that shocks to the trend component will significantly alter the implications for long run expected growth rates, and consequently have serious implications for the equity premium and market volatility.

The ARMA(1,1) specification used in this paper can also be derived from a specific trendcycle model for the level of dividends. For example, let $\log D_{t} \equiv Y_{t}=T_{t}+S_{t}$ where $T_{t}$ is the trend component and $S_{t}$ is the cyclical component. If one assumes that the trend for $Y$ follows a exponential smoothing process, where $T_{t}=\omega T_{t-1}+(1-\omega) Y_{t}$, and the cyclical part follows an $\operatorname{AR}(1)$ process, with $\operatorname{AR}(1)$ parameter of $\rho$. Then the growth rate $g_{t+1}=Y_{t+1}-Y_{t}$ follows an $\operatorname{ARMA}(1,1)$ process as discussed in section 2.1. Note that this is one of the many ways to characterize the trend and cyclical components so that the implied growth rate process is an $\operatorname{ARMA}(1,1)$. This description of the trend and cycle is analogous to the HP filter which, as opposed to this, is a two-sided filter.

Finally, in Figure 1 we plot the predicted trend growth rate component of the HP filtered series against the expected growth rate process implied by the estimated ARMA $(1,1)$ process. The two track each other very well although the $\operatorname{ARMA}(1,1)$ is clearly not as smooth as the HP-filtered trend growth rate, which as stated earlier is a two-sided filter. Overall, the HP filter implications for the expected growth rate process and the $\operatorname{ARMA}(1,1)$ process, despite some differences, provides the same broad message - the expected growth rate process is very persistent.

\subsection{Estimation and Asset Pricing Implications}

We now turn to the empirical asset pricing implications of the model. We provide estimation

results for the model. Subsequent to that we provide a few calibration experiments designed 
to highlight the economics of the model.

\subsubsection{Estimation Results and Asset Market Implications}

Table 3 provides the core estimation results of our models. Panel A in the table depicts the relevant data statistics. Panels $\mathrm{B}$ and $\mathrm{C}$ provide the parameter estimates of the exogenous processes (i.e., the $\operatorname{ARMA}(1,1)-\operatorname{GARCH}(1,1)$ specification), preferences, and asset return moments of interest. The asset markets data, in addition to the growth rate process, contain valuable information regarding the growth dynamics itself. Consequently, the preference parameters $(\delta, \gamma$ and $\psi)$ are estimated in conjunction with the growth rate parameters $(\rho$, $\omega, \nu_{1}$, and $\left.\omega_{v}\right)$. These parameters are estimated by exploiting theoretical restrictions derived earlier on the equity premium, the level of the risk-free rate, the volatility of the market return and the risk free rate as well as the moment conditions for estimating the growth rate process as discussed above. ${ }^{10}$ Further note that in our estimations the mean per-capita consumption growth rate is set at $2.4 \%$ per annum.

Panel B provides the results for the dividend model for which $\lambda=1$ and $\tau=1$, that is when consumption and dividends are the same. As reported in the first four columns of Panel B of Table 3 the estimated $\rho$ and $\omega$, at 0.977 and 0.864 are marginally higher than their point estimates in Table 2 (where $\rho=0.965$ and $\omega=0.851$ ). The estimated preference parameters imply a risk aversion of 1.88 and an elasticity of intertemporal substitution of 2.87. In terms of the asset pricing implications, the resulting level of the equity premium and risk free rate are identical to those observed in the data. The standard deviation of the market return is $19.20 \%$, which is also identical to that observed in the data. The standard deviation of the ex-ante risk-free rate is $1.3 \%$ in the model, which is only slightly higher than the volatility of the measured real risk-free rate.

In Panel $\mathrm{C}$ we estimate the consumption-dividend model detailed in section 3.2. We choose $\lambda$ equal to 3 and set the conditional correlation between consumption and dividends to zero (i.e., $\tau=0$ ). This choice for the leverage parameter $\lambda$ ensures that we match the respective volatilities of consumption and dividend growth rates. As stated under Monthly Statistics of Table 3, the annualized monthly volatility of consumption is $1.8 \%$ comparable to that in post-war data. Further, the dividend volatility, which is $5.5 \%$, is identical to that in our entire sample. ${ }^{11}$ Note, that the unconditional correlation of consumption and dividend

\footnotetext{
${ }^{10} \mathrm{As}$ in Campbell and Koo (1997) we have also solved the model using numerical techniques and find that the Campbell-Shiller approximation used to derive the approximate analytical solutions provide very good solutions. All the quantitative results reported for our estimated parameters are very close to that found in the numerical solutions, as long as we confine attention to IES parameters less than 3.0 and risk aversion of less than 10, and choose $\rho$ which is less than 0.995 . Note that the estimated models satisfy all these restrictions.

${ }^{11}$ Note that monthly consumption (non-durables and services) data is available only from 1959 . In addition,
} 
growth rate is only 0.17 .

The estimated parameters for growth rate dynamics, given in Panel C of Table 3 are quite similar to those of Panel B and hence only marginally different than those given in Table 2. In this case, the estimated risk aversion at 5.55 is higher, and elasticity of substitution parameter at 1.94 is lower than that in Panel $\mathrm{B}$. The effect of increasing $\lambda$ is to lower the volatility of consumption, consequently to match the observed equity premium a higher risk aversion is warranted. In terms of asset pricing moments, this model matches entirely the levels of the risk free rate, the equity premium and the volatility of the market return. The risk free rate volatility is now $0.51 \%$ - somewhat lower than the volatility of our measured real risk free-rate.

It is worth noting that the differences between the preference parameter estimates in Panel B and Panel C are primarily due to differences in the volatility of consumption growth rates, as captured by different choices of $\lambda^{12}$ Lowering the value of $\lambda$ while fixing the volatility of dividend growth rate increases the consumption growth rate volatility. At the same time the magnitude of $A_{1, m}$ is increasing in $\lambda$ and $\psi$. Both of these parameters have first order effects on the volatility of the market return. To capture market volatility, a rise in $\lambda$ accommodates a lower value of $\psi$ to capture market volatility, at the same time as consumption volatility is lowered, to capture the equity premium a larger risk-aversion parameter is needed. This explains the differences in Panel B and C.

\subsubsection{Additional Asset Market Implications}

Table 4 provides some additional implications for the two estimated models in Table 3. First, it is well known that price-dividend ratios are quite volatile and are very persistent. The first three columns demonstrate that the models' predictions regarding the volatility and first two autocorrelation of the price dividend ratios are comparable to that in the data. The volatility of $\log$ price-dividend ratios in the data is about 0.32 and 0.26 in the consumption-dividend model ${ }^{13}$. Further, the first two autocorrelations of the models' log price-dividend ratios are essentially identical to those observed in the data.

A well recognized important dimension is that dividend yields predict multi-horizon returns, where a rise in current dividend yield predicts a rise in future expected returns. Our model performs quite well in reproducing this important feature of the data. In columns 4-9

this choice of $\lambda$ and $\tau$ also allows us to match the annual volatility of consumption and dividend growth rates observed for the entire sample 1927-1998. The volatility of the annual dividend and consumption growth rate, in the data, is 11.49 and 2.92 , respectively. Temporally aggregating the monthly growth rate dynamics based on Panel $\mathrm{C}$ in Table 3 the comparable volatilities of annual growth rates (based on Monte-Carlo simulations) are 9.04 and 3.4 respectively.

${ }^{12}$ Our results are not particularly sensitive to the choice of $\tau$ for values less than 0.3 .

${ }^{13} \mathrm{It}$ is worth noting that excluding the last 5 years in our sample, results in $\sigma(p-d)$ being only 0.28 . 
in Table 4 we report these predictability regressions for horizons of 1,36 , and 120 months. As is evident, the model captures the positive relationship between expected returns and dividend yields. The slope coefficients and the corresponding $R^{2}$ 's rise with the return horizon, as in the data. Further, note that the model based slope coefficients are within one standard error of the estimated coefficients in the data. Finally, the unconditional variance of the equity premium relative to the ex-post return variance in the model is less than $2 \%$. This is important as it highlights the fact that cost of capital variation in our model is quite small - variation in price-dividend ratios is primarily due to the small predictable variation in growth rates.

In the context of this real economy, we can also explore the implications for the term premia on real bonds - the average one period excess return on an $n$ period discount bond. The explicit formulas for the real term structure and the term premia are presented in section 6.4 in Appendix A. At our point estimates real bonds have small negative risk premia (about $-0.4 \%$ and $-1.2 \%$ for a 12 and 36 month real bond respectively) - that is, real bonds provide consumption insurance to agents. This implication of our model for real bonds is consistent with the evidence provided in Evans (1998) who documents that for inflation indexed bonds in the U.K. (1983-1995) the term premia is significantly negative (less than $-2 \%$ at 1 year horizon) while the term premia for nominal bonds is slightly positive. This evidence of negative term premia on real bonds is consistent with the implications of the model. It is worth noting that the negative term premia in our model also imply that the large equity premium in the model is not a by product of a large positive term premia.

There is a large literature which documents that market return volatility displays a GARCH(1,1) pattern with fairly persistent volatility shocks (see Bollerslev (1986)). Note that this feature of the data is easily reproduced in our model. Equation (16) implies that $\sigma_{m, t}^{2}$, the market volatility process is

$$
\sigma_{m, t}^{2}=B^{2} \frac{w_{t}}{1-\nu_{1} L}+\kappa_{1} A_{2}^{2} \sigma_{w}^{2}
$$

that is the market volatility is also a $\operatorname{GARCH}(1,1)$ process the persistence of which is $\nu_{1}$. This is displayed in the last column of the table as $\rho_{1, \sigma\left(r_{m}\right)}$ - in the data this persistence parameter is 0.984 and in the model it is equal to $\nu_{1}, 0.983$. The magnitude of $\nu_{1}$ at 0.984 in the data is consistent with the evidence provided in Bollerslev, Engle, and Wooldridge (1988). Further note that innovations to market volatility relative to dividend growth rate volatility are magnified by the amount $B^{2}$, which is bigger than 1 . Finally, the implications of the consumption-dividend model for the time-series of the conditional equity premium are shown Figure 2. As growth rate volatility is high during recessions it follows, from the 
perspective of our model, that the equity premium also rises during these time periods.

\subsubsection{Magnitudes of Preference Parameters}

The above results make it clear that the consumption-dividend model with risk aversion parameter of about 5 and an intertemporal elasticity of substitution parameter (henceforth IES) of around 1.95, can indeed justify a wide range of regularities observed in asset market data. Campbell (1999) in the context of asset pricing implications with Epstein and Zin (1991) preferences and homoskedastic consumption growth rate process argues that IES is quite small in the data. Hall (1978), also reports low magnitudes for the IES. On the other hand, estimates of the IES by Attanasio and Webber (1989), who also exploit the Epstein and Zin (1991) framework, are in excess of 2. The IES estimates in Hansen and Singleton (1984), using market and T-bill returns, are also well in excess of 2. Our estimates of the IES are close to those in Attanasio and Webber (1989) and are somewhat smaller than in Hansen and Singleton (1984).

It is perhaps useful to also relate our estimation to that pursued in Epstein and Zin (1991). Our estimation approach differs from that in Epstein and Zin (1991) (and the papers cited in above) in two important ways. First, unlike the approach in these papers we estimate the preference parameters by imposing theoretical restrictions on the volatility of asset returns in conjunction with the commonly exploited restrictions on the mean risk-free rate and equity risk premium. As discussed below, the volatility of asset returns provide valuable independent information regarding the preference parameters. Second, the Epstein and Zin (1991) paper provides preference parameter estimates exploiting observed aggregate consumption growth, but assume that the return on the aggregate consumption portfolio coincides with the observed value weighted return on the market portfolio. Recall, that in equation (25) $R_{a, t+1}$, the return on the consumption portfolio, is a critical input into the IMRS. Given that the time series behavior of $R_{a, t+1}$ and $R_{m, t+1}$ can be very differentusing $R_{m, t+1}$ in place of $R_{a, t+1}$ will considerably affect the parameter estimates. In contrast, this paper estimates preference parameters without making this additional assumption and imposes the internally consistent theoretical restrictions needed to derive the return on the aggregate consumption portfolio.

It is also important to note that the standard way to measure IES can lead to considerable downward bias in estimation. As in Hall (1978), the IES is typically measured by the slope coefficient from projecting date $t+1$ consumption growth rate on the date $t$ risk-free rate. 
This slope coefficient in the context of our model is;

$$
\frac{\operatorname{cov}\left(g_{t+1}, r_{f, t}\right)}{\operatorname{var}\left(r_{f, t}\right)}=\frac{\psi}{1+\psi^{2} \Theta \frac{\operatorname{Var}\left(\sigma_{g, t}^{2}\right)}{\operatorname{Var}\left(x_{t}\right)}}
$$

where $\Theta \equiv\left\{\frac{1-\theta}{\theta}\left[B\left(-B_{p k}\right)-0.5 B^{2}\right]-B_{p k}^{2} \frac{1}{2 \theta}\right\}^{2}{ }^{14} \quad$ If growth rate innovations are homoskedastic, that is $\operatorname{Var}\left(\sigma_{g, t}^{2}\right)=0$, then the slope coefficient is equal to $\psi$, the population value of the IES. However, with stochastic volatility the measured slope coefficient is downward biased relative to the true value of the IES parameter. For example with population IES of $\psi=3$ and $\gamma=2$ and all other parameters $\left(\rho, \omega, \nu_{1}, \omega_{v}\right)$ set at their point estimates of Panel B in Table 3 the measured slope coefficient would be 0.6 . Hence, the downward bias can be sizable. Further, this is suggestive of the reasons for the differences in point estimates across different economic environments and data sets. Given the evidence in Attanasio and Webber (1989) and Hansen and Singleton (1984), and the possibility of downward bias in standard estimation of IES, it seems that our IES estimates are well within the realm of plausibility.

Using non-parametric bounds on asset prices, Hansen and Jagannathan (1991), and Cochrane and Hansen (1992) document that large risk aversion helps in justifying observed risk premia. Mehra and Prescott (1985) argue that a reasonable upper bound for risk aversion is around 10. In this sense, our estimates for risk-aversion of about 5.5 are quite low and reasonable.

\subsubsection{Calibration}

To generate intuition for the way various parameters affect the asset prices in our model we provide some additional sensitivity analysis which are reported in Tables 5-7. In these exercises we highlight the importance of the small persistent component in conjunction with the non-expected utility preferences in explaining the asset market puzzles. In addition we quantify the contribution of stochastic volatility risk in consumption growth rate dynamics in explaining risk premiums and asset return volatility.

Table 5 provides calibration results for the case in which preferences exhibit non-expected utility. The results in Panel A are based on growth rate dynamics reported in Panel $\mathrm{C}$ of Table 3 (that is, consumption-dividend model with $\lambda=3$ and $\tau=0$ ) for various values of $\gamma$ and $\psi$. For a given risk aversion, a rise in the elasticity of substitution increases the equity premium and market volatility, and at the same time lowers the risk-free rate and its

\footnotetext{
${ }^{14}$ The expression for the slope coefficient follows from recognizing that $\operatorname{cov}\left(g_{t+1}, r_{f, t}\right)=\frac{1}{\psi} \operatorname{var}\left(x_{t}\right)$ and the expression for $\operatorname{var}\left(r_{f, t}\right)$ given in equation (30) in Appendix A.
} 
volatility. Evidently, higher levels of $\psi$, for a given level of risk aversion, help the model in justifying the asset market facts.

Next we explore the importance of stochastic volatility in consumption-dividend growth rates. Panel B in Table 5 provides results when growth rate dynamics do not exhibit stochastic volatility (that is, we set $\nu_{1}=\omega_{v}=0$ ) - the rest of the parameters are held as in Panel A. A comparison across Panels A and B, with $\gamma=5.50$ and $\psi=2$ shows, that the equity premium and market volatility without stochastic volatility are about $5.3 \%$ and $16.98 \%$ as opposed to $6.4 \%$ and $19.20 \%$ with volatility risk. Hence, stochastic volatility risk contributes about $18 \%$ to both, equity risk premium and market volatility. Stated differently, in the absence of volatility risk our model would require higher risk aversion and higher elasticity of substitution to justify the observed equity premium and market volatility.

Panel $\mathrm{C}$ in Table 5 replicates the analysis above except that $\rho=.965$ and $\omega=.85-$ the univariate point estimates for dividend growth rate dynamics given in Table 2. It can be easily seen that a higher $\rho$ for a given $\gamma$ and $\psi$ increases the equity premium, lowers the risk free rate and increases the market return volatility. A comparison of Panel $\mathrm{C}$ to Panel A makes it clear that higher magnitudes of $\rho$ obviate the need to choose a larger $\psi$ and $\gamma$ to match the asset returns moments of interest. Economically, this is an outcome of the fact that larger values of $\rho$ magnify the effects of small current growth rate news on current market valuations, as discussed above in section 2.1 .

Table 6 provides results for the case in which cash-flow dynamics are i.i.d (that is $\rho=\omega$ and $\nu_{1}=\omega_{v}=0$ ) and preferences still exhibit the non-expected utility. In this case the price-dividend ratio is constant. Consequently, the market return volatility mirrors the volatility of dividend growth rates. Further, the equity premium is small and unaltered by changing $\psi$, and the level of the risk free rate is very high. This highlights the importance of a persistent component in consumption-dividend growth rates which our ARMA(1,1) specification captures.

Table 7 provides results for the standard time-non-separable preferences. Panel A assumes cash-flow dynamics are i.i.d and consumption and dividends are perfectly correlated, as in Mehra and Prescott (1985). Not surprisingly the setup reproduces the well documented inability of this model to explain asset market data. As the dividend yield is constant in this specification, the market volatility equals the volatility of the consumption-dividend process for all values of risk aversion.

In Panel B dividend growth rates follow the consumption-dividend $\operatorname{ARMA}(1,1)$ GARCH(1,1) specification. Note that now the equity risk premium is negative. In interpreting this result it is useful to recall the expression for $A_{1}$ in (13). For values of $\gamma$ (which in this case equals the reciprocal of $\psi$ ) bigger than $1, A_{1}$ is negative - a rise in 
expected growth rates lowers the price-dividend ratio. A result of this feature is that when there is a positive shock to consumption (dividends) there is a negative shock to market returns. Hence, the covariance between consumption and the market return is negative. In this case the market insures the agent's consumption and therefore the required equity premium is negative. This feature underscores the importance of separation between risk aversion and elasticity of substitution in the context of our preferred model. Overall, the key message of these tables is that neither non-expected utility nor the $\operatorname{ARMA}(1,1)-\mathrm{GARCH}(1,1)$ specification for growth rates is sufficient by itself to explain the asset market data. In our model the two channels must co-exist if the model is to match the equity premium, the level of the risk free rate, and the volatilities of the risk free rate and the market return.

Finally, note that our preferred model has quite reasonable magnitudes of risk aversion (about 5.5) and IES. If one yields on market volatility by a small amount, it is possible to drive the IES and risk aversion even lower.

\section{Conclusions}

In this paper we explore the idea that news about consumption and dividend growth rates continuously alters perceptions regarding long-term expected growth rates, and that in equilibrium this feature is important for explaining various asset market anomalies. If news about dividends has non trivial impact on long-term expected growth rates, then the capitalized value of this cash-flow would be fairly sensitive to small news. Further, if dividends are positively correlated with consumption than the dividend cash-flow may warrant a large equity premium.

We provide empirical support for the view that the observed aggregate consumptiondividend growth process contains a persistent component that imposes long term risks. In addition, we show that uncertainty of growth rates changes across time - that is, growth rate volatility is stochastic. We document that the interaction between dividend growth rate dynamics, which incorporate this idea of long term risks, in conjunction with the preferences as developed in Epstein and Zin (1989)-Weil (1989) can indeed explain many outstanding asset market puzzles. In particular, we show that such a model is capable of justifying the observed magnitudes of the equity premium, the low risk free rate and the volatility of market return, dividend-yield, and the risk free rate. In addition, the model is capable of justifying the predictive relation between dividend yields and returns and the well documented GARCH-type stochastic volatility in ex-post equity returns. In the model much of the variability in equity prices is due to news about growth rates while variation in the cost of capital is fairly small. 
It seems that the framework developed in this paper has sharp implications for costs of business cycle fluctuations and the cross-section of asset returns - we plan to explore these issues in a separate paper. 


\section{References}

Abel, A., (1990), Asset prices under habit formation and catching up with the joneses, American Economic Review 80, 38-42.

Abel, A., (1999), Risk premia and term premia in general equilibrium, Journal of Monetary Economics 43, 3-33.

Andrews, D. and W. Ploberger, (1996), Testing for serial correlation against an $A R M A(1,1)$ process, Journal of the American Statistical Association 91, 1331-1342.

Attanasio, O. and W. Webber, (1989), Intertemporal substitution, risk aversion and the euler equation for consumption, Economic Journal 99, 59-73.

Bansal, R. and J. Coleman, (1997), A monetary explanation of the equity premium, term premium and the riskfree rate puzzles, Journal of Political Economy 104, 1135-1171.

Bansal, R. and C. Lundblad, (1999), Fundamental values and asset returns in global equity markets, Working Paper, Duke University.

Bansal, R. and A. Yaron, (2000), Risks for the long run: A potential resolution of asset pricing puzzles, Unpublished Manuscript, June 2000.

Barsky, R. B. and B. DeLong, (1993), Why does the stock market fluctuate, Quarterly Journal of Economics 108, 291-311.

Bollerslev, T., (1986), Generalized autoregressive conditional heteroskedasticity, Journal of Business 307-327.

Bollerslev, T., R. Engle, and J. Wooldridge, (1988), A capital asset pricing model with time varying covariances, Journal of Political Economy 96, 116-131.

Bollerslev, T. and R. Hodrick, (1995), Financial market efficiency tests, chapter 9, Handbook of Applied Econometrics.

Campbell, J., (1999), Asset prices, consumption and the business cycle, chapter 19, 12311303, Elsevier Science, North-Holland, In HandBook of Macroeconomics, Volume 1, John B. Taylor and Michael Woodford, editors.

Campbell, J. Y., (1993), Intrertemporal asset pricing without consumption data, American Economic Review 83, 487-512.

Campbell, J. Y., (1996), Understanding risk and return, Journal of Political Economy 104, 298-345.

Campbell, J. Y. and J. Cochrane, (1999), By force of habit: a consumption-based explanation of aggregate stock market behavior, Journal of Political Economy 107, 205-251. 
Campbell, J. Y. and H. Koo, (1997), A comparison of numerical and analytical approximate solutions to an intertemporal consumption choice problem, Journal of Economic Dynamics and Control 21, 273-295.

Campbell, J. Y. and R. Shiller, (1988), The dividend-price ratio and expectations of future dividends and discount factors, Review of Financial Studies 1, 195-227.

Cecchetti, S., P.-S. Lam, and N. Mark, (1990), Mean reversion in equilibrium asset prices, American Economic Review 80, 398-419.

Cochrane, J. and L. Hansen, (1992), Asset Pricing Lessons for Macroeconomics, MIT Press, Cambridge, In NBER Macroeconimcs Annual 1992 eds. O. Blanchard and S. Fischer.

Constantinides, G. M., (1990), Habit formation: A resolution of the equity premium puzzle, Journal of Political Economy 98, 519-543.

Constantinides, G. M. and D. Duffie, (1996), Asset pricing with heterogeneous consumers, Journal of Political Economy 104, 219-240.

Easton, P. D. and M. Zmijewski, (1989), Cross-sectional variation in the stock market response to the announcement of accounting earnings, Journal of Accounting and Economics 11, 117-141.

Epstein, L. G. and S. Zin, (1989), Substitution, risk aversion and the temporal behavior of consumption and asset returns: A theoretical framework, Econometrica 57, 937-969.

Epstein, L. G. and S. Zin, (1991), Substitution, risk aversion and the temporal behavior of consumption and asset returns ii: An empirical analysis, Journal of Political Economy 99, 1263-286.

Evans, M., (1998), Real rates, expected inflation and inflation risk premia, Journal of Finance 976-992.

Hall, R., (1978), Stochastic implications of the life cylce permanent income hypothesis: Theory and evidence, Journal of Political Economy 86, 971-88.

Hansen, L., T. Sargent, and T. Tallarini, (1999), Robust permanent income and pricing, Review of Economic Studies 66, 873-907.

Hansen, L. P. and R. Jagannathan, (1991), Implications of security market data for models of dynamic economies, Journal of Political Economy 99, 225-262.

Hansen, L. P. and K. Singleton, (1984), Generalized instrumental variables estimation of nonlinear rational expectations models:errata, Econometrica 52, 267-268.

Heaton, J., (1995), An empirical investigation of asset pricing with temporally dependent preference specification, Econometrica 63, 681-718.

Heaton, J. and D. J. Lucas, (1996), Evaluating the effects of incomplete markets on risk sharing and asset pricing, Journal of Political Economy 104, 443-487. 
Hodrick, R., (1992), Dividend yields and expected stock returns: Alternative procedures for inference and measurement, Review of Financial Studies 5, 357-386.

Hodrick, R. and E. Prescott, (1997), Postwar u.s. business cycles: An empirical investigation, Journal of Money Credt and Banking 29, 1-16.

Kandel, S. and R. Stambaugh, (1991), Asset returns and intertemporal preferences, Journal of Monetary Economics 27, 39-71.

Kormendi, R. and R. Lipe, (1987), Earnings innovations, earnings persistence and stock returns, Journal of Business 60, 323-345.

Kydland, F. E. and E. C. Prescott, (1982), Time to build and aggregate fluctuations, Econometrica 50, 1345-1370.

LeRoy, S. F. and R. D. Porter, (1981), The present value relation: Tests based on implied variance bounds, Econometrica 49, 555-574.

Lucas, R., (1978), Asset prices in an exchange economy, Econometrica 46, 1429-1445.

McCallum, B., (1983), On non-uniqueness in rational expectations models, Journal of Monetary Economics 11, 139-168.

Mehra, R. and E. Prescott, (1985), The equity puzzle, Journal of Monetary Economics 15, $145-61$.

Newey, W. K. and K. D. West, (1987), A simple, positive semi-definite, heteroskedasticity and autocorrelation consistent covariance matrix, Econometrica 55, 703-708.

Shephard, N. G. and A. Harvey, (1990), On the probability of estimating a deterministic component in the local level model, Journal of Time Series Analysis 11, 339-347.

Shiller, R., (1981), Do stock prices move too much to be justified by subsequent changes in dividends?, The American Economic Review 71, 421-436.

Weil, P., (1989), The equity premium puzzle and the risk free rate puzzle, Journal of Monetary Economics 24, 401-421. 


\section{Table 1 : Data Description}

\begin{tabular}{|c|c|c|c|c|}
\hline & $\pi$ & $r_{f}$ & $r_{m}$ & Div. Growth $-g$ \\
\hline \multicolumn{5}{|c|}{ Panel A: Monthly Frequency } \\
\hline$\mu$ & $\begin{array}{c}3.642 \\
(0.105)\end{array}$ & $\begin{array}{c}0.557 \\
(0.140)\end{array}$ & $\begin{array}{c}6.997 \\
(2.265)\end{array}$ & $\begin{array}{c}3.519 \\
(0.654)\end{array}$ \\
\hline$\sigma$ & $\begin{array}{c}0.892 \\
(0.026)\end{array}$ & $\begin{array}{c}1.191 \\
(0.047)\end{array}$ & $\begin{array}{c}19.201 \\
(0.969)\end{array}$ & $\begin{array}{c}5.550 \\
(0.422)\end{array}$ \\
\hline$\rho_{1}$ & $\begin{array}{c}0.985 \\
(0.011)\end{array}$ & $\begin{array}{c}0.979 \\
(0.010)\end{array}$ & $\begin{array}{c}0.102 \\
(0.056)\end{array}$ & $\begin{array}{c}0.252 \\
(0.069)\end{array}$ \\
\hline$\rho_{2}$ & $\begin{array}{c}0.971 \\
(0.014)\end{array}$ & $\begin{array}{c}0.953 \\
(0.015)\end{array}$ & $\begin{array}{c}-0.016 \\
(0.051)\end{array}$ & $\begin{array}{c}0.227 \\
(0.029)\end{array}$ \\
\hline
\end{tabular}

$r_{f}$ is the real risk free rate derived by subtracting a trailing 12-month average of inflation $(\pi)$ from the one month T-Bill. $r_{m}$ is the continuous real return on the Value Weighted NYSE taken from CRSP. We construct a monthly dividend series using the Value Weighted return on NYSE. The de-seasonalized level of dividends are constructed using a trailing 12 month moving average of real dividends. The statistics reported above are for continuous (i.e. $\log$ ) growth rates constructed from this time series for the level of dividends. The sample period is 1927:01-1998:12. All return data is from CRSP and inflation is CPI based on BLS. Standard errors are Newey and West (1987) corrected using 12 lags. 


\section{Table 2 : Estimating Dividend Growth Rate Dynamics}

\begin{tabular}{rccccccc}
\hline \multicolumn{10}{c}{$\mu$} & $\rho$ & $\omega$ & $\sigma_{\eta}$ & $\nu_{0}$ & $\nu_{1}$ & $\omega_{v}$ \\
\hline \hline \multicolumn{7}{c}{ Panel A: Monthly Frequency } \\
\hline Estimates & .000092 & .965 & .851 & .0147 & & & \\
S.E. & $(.00011)$ & $(.016)$ & $(.0315)$ & & & & \\
& & & & & & & \\
Estimates & .000092 & .965 & .851 & .0147 & .00000376 & .983 & .951 \\
S.E. & $(.00012)$ & $(.016)$ & $(.0316)$ & & $(.000005)$ & $(.025)$ & $(.055)$
\end{tabular}

Panel B: HP-filtered dynamics- Monthly data

\begin{tabular}{rccc}
\hline & $\rho_{1}$ & $\rho_{2}$ & Var-Ratio \\
Growth in HP-trend & .998 & .992 & $11.8 \%$ \\
Growth in HP-cyclical & .04 & .015 & $88.2 \%$ \\
& & & \\
\hline \hline
\end{tabular}

The model for dividend growth rate is:

$$
g_{t+1}=\mu+\rho g_{t}+\eta_{t+1}-\omega \eta_{t}
$$

The GARCH $(1,1)$ model for $\eta$ implies the stochastic volatility model (12) :

$$
\sigma_{g, t+1}^{2}=\nu_{0}+\nu_{1} \sigma_{g, t}^{2}+\left(\nu_{1}-\omega_{v}\right)\left(\eta_{t+1}^{2}-\sigma_{g, t}^{2}\right) .
$$

The moments used in estimation of the $\operatorname{ARMA}(1,1)$ model are: $E\left[\eta_{t} g_{t-1}, \eta_{t} \eta_{t-1}, \eta_{t}\right]=\mathbf{0}$. The ARMA(1,1) parameters underlying the $\operatorname{GARCH}(1,1)$ specification are estimated in analogous manner. The parameters $\rho_{1}, \rho_{2}$ are the first and second autocorrelations and Var-Ratio is the variance of the HP-filtered component growth rate relative to the observed growth rate. Standard Error are Newey and West (1987) corrected using 12 lags. 


\section{Table 3 : Estimation Results and Asset Pricing Implications}

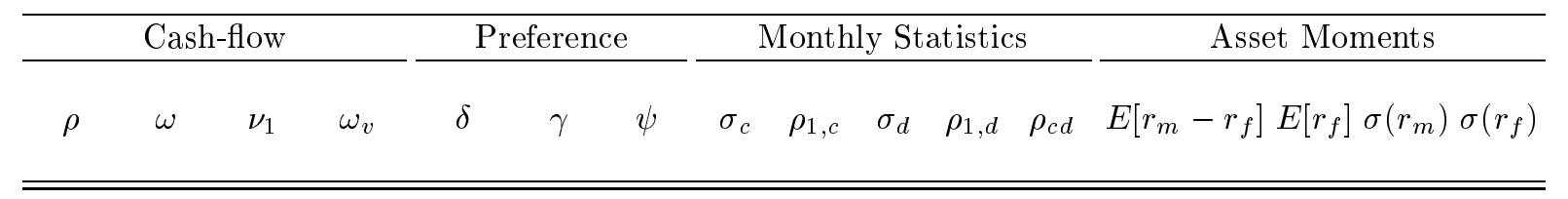

\begin{tabular}{|c|c|c|c|c|c|}
\hline \multicolumn{6}{|c|}{ Panel A: Data } \\
\hline & $\begin{array}{ll}5.55 & .26\end{array}$ & 6.44 & 0.56 & 19.20 & 1.19 \\
\hline \multicolumn{6}{|c|}{ Panel B: $\lambda=1, \tau=1$} \\
\hline $\begin{array}{cccccc}.977 & .864 & .983 & .951 & .997 & 1.88 \\
(.006) & (.032) & (.005) & (.029) & (.001) & (.47)\end{array}$ & $\begin{array}{lllll}2.78 & 5.43 & .27 & 5.43 & .27 \\
(.26) & (.28) & (.07) & (.28) & (.07)\end{array}$ & 6.44 & 0.55 & 19.20 & 1.31 \\
\hline \multicolumn{6}{|c|}{ Panel C: $\lambda=3, \tau=0$} \\
\hline $\begin{array}{cccccc}.974 & .860 & .983 & .950 & .998 & 5.55 \\
(.007) & (.033) & (.006) & (.031) & (.001) & (1.65)\end{array}$ & $\begin{array}{ccccc}1.94 & 1.81 & .25 & 5.47 & .17 \\
(.64) & (.15) & (.07) & (.36) & (.06)\end{array}$ & $\begin{array}{l}.17 \\
.06)\end{array}$ & 0.55 & 19.20 & 0.51 \\
\hline
\end{tabular}

In Panel A we provide the data counterpart to the asset moments of interest. Note that $r_{m}$ and $r_{f}$ are the continuous (i.e., logged) return on the market and the risk-free rate respectively. The equity premium, is denoted as $E\left[r_{m}-r_{f}\right]$. All standard deviations are annualized monthly standard deviations, that is monthly standard deviations are multiplied by $\sqrt{1} 2 \times 100$ and all monthly mean returns are annualized. In Panels B and $\mathrm{C}$ the preference parameters (risk aversion $\gamma$, elasticity of substitution $\psi$, and discount factor $\delta$ ) and the $\operatorname{ARMA}(1,1)-\operatorname{GARCH}(1,1)$ time-series parameters are jointly estimated. The moment conditions used in the estimation are based on minimizing the difference between those observed in the data and the corresponding population moments implied by the model for $\left[E\left[r_{m}-r_{f}\right], E\left[r_{f}\right], \sigma^{2}\left(r_{m}\right), \sigma^{2}\left(r_{f}\right)\right]$ in conjunction with the moments conditions for estimating the dividend growth rate parameters as discussed in Table 2. Panel $\mathrm{B}$ describes the estimation results for a model in which consumption equals dividends. The dynamics for dividend growth include the $\operatorname{ARMA}(1,1)-\operatorname{GARCH}(1,1)$ specification given in (7). In Panel $\mathrm{C}$, we estimate the ARMA(1,1)-GARCH(1,1) consumption- dividend model described in section 3.2. We set the leverage factor of dividends, $\lambda=3$ and the conditional correlation between consumption and dividends, $\tau=0$. All estimations use a two-step GMM procedure with a Newey and West (1987) covariance matrix with 12 lags. 


\section{Table 4 : Additional Model Implications}

\begin{tabular}{|c|c|c|c|c|c|c|c|c|c|}
\hline$\sigma(p-d)$ & $\rho_{1, p-d}$ & $\rho_{2, p-d}$ & $\beta_{1}$ & $\beta_{36}$ & $\beta_{120}$ & $R_{1}^{2}$ & $R_{36}^{2}$ & $R_{120}^{2}$ & $\rho_{1, \sigma\left(r_{m}\right)}$ \\
\hline \multicolumn{10}{|c|}{ Panel A: Data } \\
\hline 0.32 & .979 & .956 & $\begin{array}{c}.007 \\
(.005)\end{array}$ & $\begin{array}{c}.37 \\
(.081)\end{array}$ & $\begin{array}{c}1.08 \\
(.161)\end{array}$ & .002 & .11 & .38 & .984 \\
\hline \multicolumn{10}{|c|}{ Panel B: $\lambda=1, \tau=1$} \\
\hline 0.22 & .970 & .948 & -.003 & 1.21 & 1.23 & .004 & .21 & .24 & .983 \\
\hline \multicolumn{10}{|c|}{ Panel C: $\lambda=3, \tau=0$} \\
\hline 0.26 & .972 & .948 & .003 & 1.14 & 1.20 & .001 & .33 & .36 & .983 \\
\hline
\end{tabular}

The first column, $\sigma(p-d)$, is the standard deviation of $\log$ price dividend ratio and the next two columns are the first two autocorrelations of the $p-d$. The entries in next six column are the $\beta$ 's and $R^{2}$ from the following regression:

$$
r_{m, t+1}+\ldots+r_{m, t+h o r i z o n}=\alpha+\beta_{\text {horizon }} \log \left(D_{t} / P_{t}\right)+\epsilon_{t, t+\text { horizon }}
$$

applied to observed data and data generated by the $\operatorname{GARCH}(1,1)$ model estimated in Panel $\mathrm{B}$ and $\mathrm{C}$ in Table 3. The panels correspond the the estimates of Panels B-C in Table 3. $\rho_{1, \sigma\left(r_{m}\right)}$ is the first order autocorrelation coefficient of the conditional volatility of $r_{m}$. 


\section{Table 5 : Calibration - Non Expected Utility: Consumption- Dividend Model: $\lambda=3$}

\begin{tabular}{lllllll}
\hline & $\psi$ & $\psi$ & $E\left[r_{m}-r_{f}\right]$ & $E\left[r_{f}\right]$ & $\sigma\left(r_{m}\right)$ & $\sigma\left(r_{f}\right)$ \\
\hline \hline
\end{tabular}

Panel A: Using Estimates from Panel C in Table 3

$\begin{array}{llllll}2.50 & 0.50 & 0.15 & 5.38 & 8.34 & 1.67 \\ 2.50 & 2.00 & 1.36 & 1.32 & 17.09 & 0.43 \\ 2.50 & 3.00 & 1.56 & 0.81 & 18.14 & 0.31 \\ & & & & & \\ 3.50 & 0.50 & 0.70 & 5.46 & 8.48 & 1.67 \\ 3.50 & 2.00 & 2.80 & 1.07 & 17.50 & 0.45 \\ 3.50 & 3.00 & 3.09 & 0.52 & 18.58 & 0.34 \\ & & & & & \\ 5.50 & 0.50 & 2.11 & 5.75 & 9.29 & 1.67 \\ 5.50 & 2.00 & 6.34 & 0.50 & 19.20 & 0.50 \\ 5.50 & 3.00 & 6.88 & -0.15 & 20.36 & 0.43\end{array}$

Panel B: As Panel A, without Volatility Risk, $\nu_{1}=\omega_{v}=0$

$\begin{array}{llllll}5.50 & 0.50 & 1.73 & 5.57 & 8.34 & 1.67 \\ 5.50 & 2.00 & 5.31 & 0.63 & 16.98 & 0.42 \\ 5.50 & 3.00 & 5.76 & 0.02 & 18.02 & 0.28\end{array}$

Panel C: As Panel A, with $\rho=.965, \omega=0.851$

\begin{tabular}{llllll}
2.50 & 0.50 & 0.08 & 5.34 & 7.22 & 1.42 \\
2.50 & 2.00 & 0.85 & 1.46 & 13.29 & 0.36 \\
2.50 & 3.00 & 0.97 & 1.00 & 14.05 & 0.25 \\
& & & & & \\
5.50 & 0.50 & 1.16 & 5.38 & 7.48 & 1.42 \\
5.50 & 2.00 & 3.62 & 0.92 & 14.14 & 0.40 \\
5.50 & 3.00 & 3.93 & 0.39 & 14.96 & 0.32 \\
& & & & & \\
7.50 & 0.50 & 2.14 & 5.52 & 7.91 & 1.42 \\
7.50 & 2.00 & 6.09 & 0.50 & 15.25 & 0.44 \\
7.50 & 3.00 & 6.57 & -0.11 & 16.14 & 0.37 \\
\hline \hline
\end{tabular}

This table provides sensitivity analysis for the effects $\gamma$ and $\psi$ have on asset prices. The calibration results are based on the consumption-dividend model of equation (23). In Panel A the growth rate dynamics are based on the parameter estimates in Panel $\mathrm{C}$ in Table 3. In Panel B the parameters are the same as in Panel A except that there is no stochastic volatility in consumption and dividend growth rates - that is, $\nu_{1}=\omega_{v}=0$. In Panel $\mathrm{C}$ of this table the parameters are the same as in Panel A above except that $\rho=.965$ and $\omega=0.851$ the point estimates of the univariate dividend growth rates described in Table 2 . 
Table 6 : Calibration-Non Expected Utility, Dividend Growth is i.i.d, $\rho=\omega, \nu_{1}=\omega_{v}=0, \lambda=3$

\begin{tabular}{cccccc}
\hline$\gamma$ & $\psi$ & $E\left[r_{m}-r_{f}\right]$ & $E\left[r_{f}\right]$ & $\sigma\left(r_{m}\right)$ & $\sigma\left(r_{f}\right)$ \\
\hline \hline & & & & \\
\multicolumn{7}{c}{ Panel A: $\tau=1$} \\
\hline 2.50 & 0.50 & 0.10 & 5.91 & 5.55 & 0.00 \\
2.50 & 4.00 & 0.10 & 1.75 & 5.55 & 0.00 \\
& & & & & \\
3.50 & 0.50 & 0.21 & 5.86 & 5.55 & 0.00 \\
3.50 & 2.50 & 0.21 & 2.08 & 5.55 & 0.00 \\
3.50 & 4.00 & 0.21 & 1.73 & 5.55 & 0.00 \\
& & & & & \\
4.00 & 0.50 & 0.26 & 5.83 & 5.55 & 0.00 \\
4.00 & 2.50 & 0.26 & 2.07 & 5.55 & 0.00 \\
4.00 & 4.00 & 0.26 & 1.72 & 5.55 & 0.00 \\
& & & & & \\
& & Panel B: $\tau=0$ & & \\
\hline 2.50 & 0.50 & -0.15 & 5.91 & 5.55 & 0.00 \\
2.50 & 2.50 & -0.15 & 2.11 & 5.55 & 0.00 \\
2.50 & 4.00 & -0.15 & 1.75 & 5.55 & 0.00 \\
& & & & & \\
3.50 & 0.50 & -0.15 & 5.86 & 5.55 & 0.00 \\
3.50 & 2.50 & -0.15 & 2.08 & 5.55 & 0.00 \\
3.50 & 4.00 & -0.15 & 1.73 & 5.55 & 0.00 \\
& & & & & \\
4.00 & 0.50 & -0.15 & 5.83 & 5.55 & 0.00 \\
4.00 & 2.50 & -0.15 & 2.07 & 5.55 & 0.00 \\
4.00 & 4.00 & -0.15 & 1.72 & 5.55 & 0.00 \\
& & & & & \\
\hline \hline
\end{tabular}

This tables provide sensitivity analysis for the effect i.i.d dividend growth rate has on asset prices when preferences are Epstein and Zin (1989). The calibration is based on the consumption-dividend model. $\rho$ is set at .974 as estimated in Panel $\mathrm{C}$ of Table 3 and $\omega$ is set equal to $\rho$ and $\nu_{1}=\omega_{v}=0$. 


\section{Table 7 : Calibration - Expected Utility}

\begin{tabular}{|c|c|c|c|c|c|}
\hline$\gamma$ & $\psi=\frac{1}{\gamma}$ & $E\left[r_{m}-r_{f}\right]$ & $E\left[r_{f}\right]$ & $\sigma\left(r_{m}\right)$ & $\sigma\left(r_{f}\right)$ \\
\hline \multicolumn{6}{|c|}{ Panel A: Growth Rate are i.i.d, $\rho=\omega, \tau=1, \nu_{1}=\omega_{v}=0$} \\
\hline $\begin{array}{r}2.00 \\
5.00 \\
10.00 \\
15.00 \\
40.00\end{array}$ & $\begin{array}{l}0.50 \\
0.20 \\
0.10 \\
0.07 \\
0.03\end{array}$ & $\begin{array}{l}0.05 \\
0.35 \\
0.87 \\
1.38 \\
3.95\end{array}$ & $\begin{array}{c}6.41 \\
13.25 \\
23.97 \\
33.83 \\
70.30\end{array}$ & $\begin{array}{l}5.55 \\
5.55 \\
5.55 \\
5.55 \\
5.55\end{array}$ & $\begin{array}{l}0.00 \\
0.00 \\
0.00 \\
0.00 \\
0.00\end{array}$ \\
\hline \multicolumn{6}{|c|}{ Panel B: Growth Rate process is from Table 3 Panel C } \\
\hline $\begin{array}{r}2.00 \\
5.00 \\
10.00 \\
15.00 \\
40.00\end{array}$ & $\begin{array}{l}0.50 \\
0.20 \\
0.10 \\
0.07 \\
0.03\end{array}$ & $\begin{array}{c}-0.28 \\
-1.04 \\
-21.33 \\
-99.33 \\
-5326.66\end{array}$ & $\begin{array}{c}6.43 \\
13.34 \\
24.32 \\
34.62 \\
75.94\end{array}$ & $\begin{array}{c}11.63 \\
9.61 \\
54.83 \\
128.52 \\
1023.19\end{array}$ & $\begin{aligned} 1.68 \\
4.20 \\
8.40 \\
12.61 \\
33.96\end{aligned}$ \\
\hline
\end{tabular}

This table provides sensitivity analysis of the effect risk aversion has on asset prices under expected utility preferences. In Panel A consumption and dividend growth rates are i.i.d and are perfectly correlated (i.e., $\omega=\rho$, and $\tau=1$ ), there is no volatility risk (i.e., $\omega_{v}=\nu_{1}=0$ ) and $\lambda=3$. Panel B provides information using parameters reported in Panel $\mathrm{C}$ of Table 3. In all experiments $\beta=.999$. 
Figure 1

HP filtered trend and fitted $\operatorname{ARMA}(1,1)$

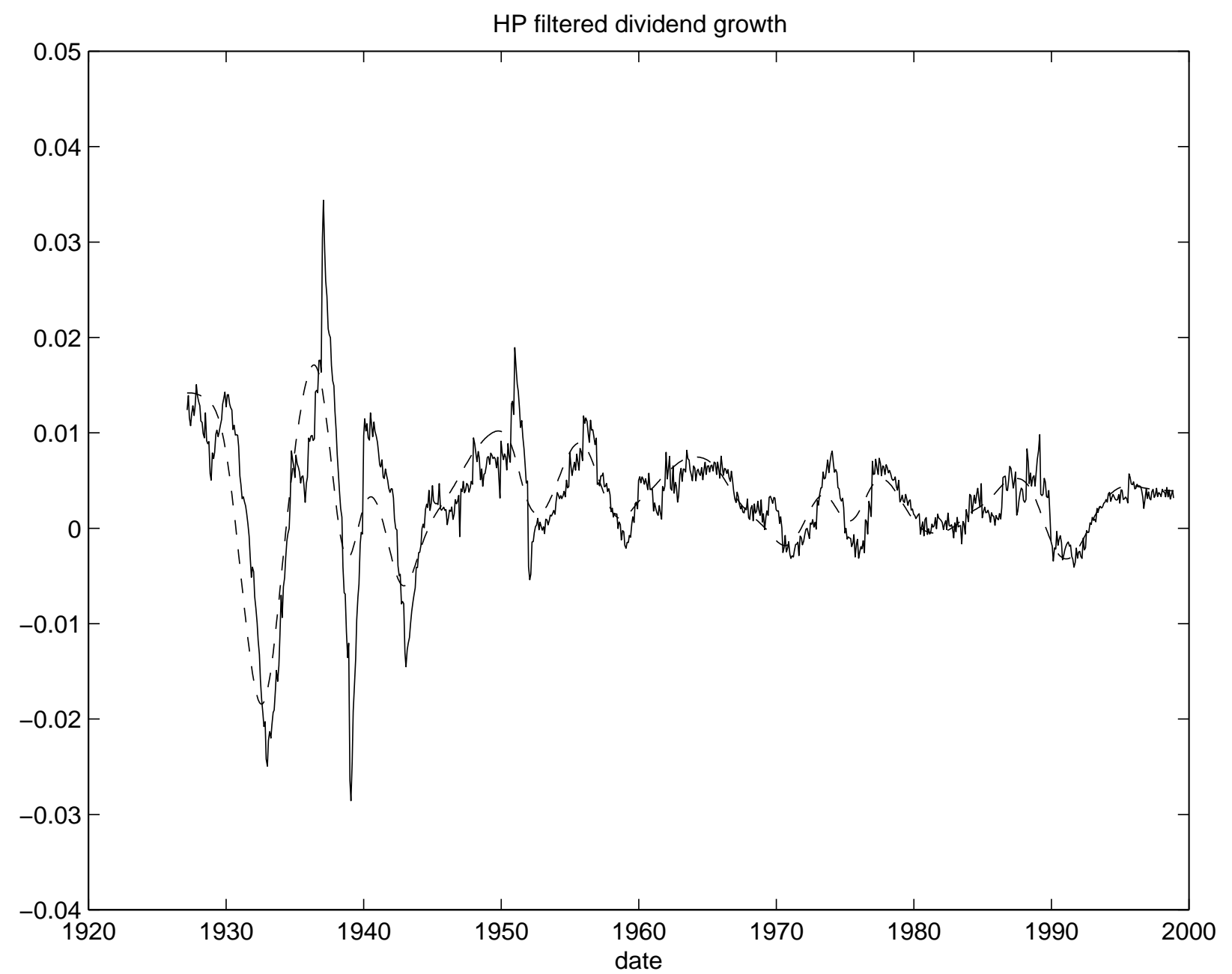

The figure depicts the fitted process for dividend growth rates from the trend component of the HP filter and the $\operatorname{ARMA}(1,1)$ estimation (Table 2). 


\section{Figure 2}

\section{The Conditional Equity Premium}

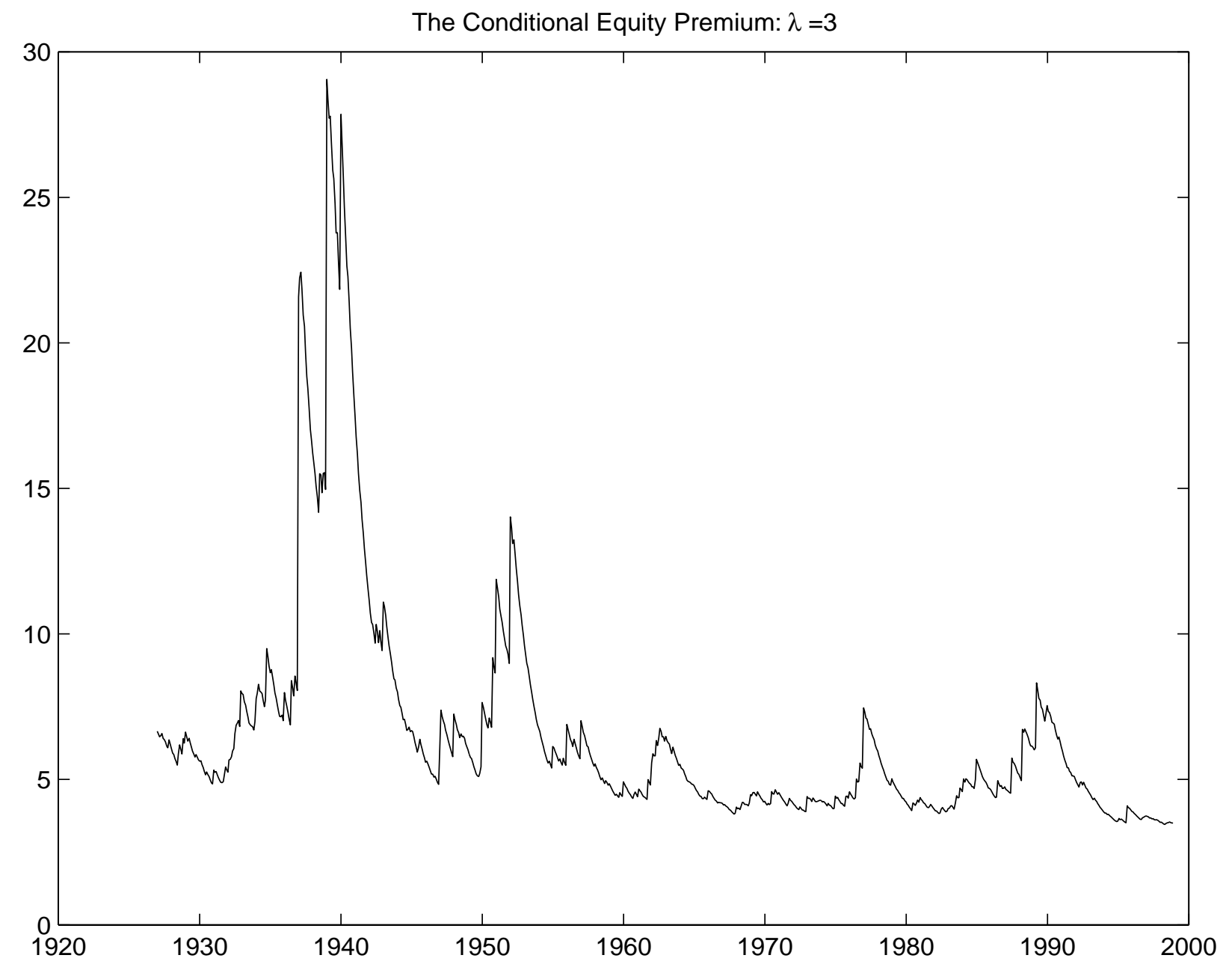

The figure depicts the conditional equity premium based on the estimated ARMA(1,1)GARCH(1,1) model in Panel B of Table 3. The conditional equity premium is in terms of percent per-annum. 


\section{Appendix-A}

\section{1 $C=D$ Model}

Recall that based on section 2.1 the consumption process with stochastic volatility is,

$$
\begin{aligned}
g_{t+1} & =x_{t}+\sigma_{g, t} \eta_{c, t+1} \\
x_{t+1} & =\mu+\rho x_{t}+(\rho-\omega) \sigma_{g, t} \eta_{c, t+1} \\
\sigma_{g, t+1}^{2} & =\nu_{0}+\nu_{1} \sigma_{g, t}^{2}+w_{t+1}
\end{aligned}
$$

To map this into equations (7), (9), and (12), note that $\sigma_{c, t} \eta_{c, t+1} \equiv \eta_{t+1}$.

The IMRS (Intertemporal Marginal Rate of Substitution) for this economy.

$$
\ln M_{t+1}=\theta \ln \delta-\frac{\theta}{\psi} g_{t+1}+(\theta-1) r_{a, t+1}
$$

Using this IMRS and the standard asset pricing condition that $E_{t}\left[M_{t+1} R_{a, t+1}\right]=E_{t}\left[\exp \left(\theta \ln \delta-\frac{\theta}{\psi} g_{t+1}+\right.\right.$ $\left.\left.\theta r_{a, t+1}\right)\right]=1$, for $R_{a, t+1}$, where $\log \left(R_{a, t+1}\right) \equiv r_{a, t+1}$. To derive the solution for the endogenous variable $z_{t}$ we substitute the approximation $r_{a, t+1}=\kappa_{0}+\kappa_{1} z_{t+1}-z_{t}+g_{t+1}$ into the standard Euler condition for $R_{a}$ (see (4), and conjecture that $\left.z_{t}=A_{0}+A_{1} x_{t}+A_{2} \sigma_{g, t}^{2}\right)$.

Given the conditional normality of $g, x$ and $\sigma_{g, t}^{2}$, the conditional mean in (4) must equal $\exp \left(c_{y, t}+\right.$ $\left.\operatorname{var}_{y, t} / 2\right)=1$, where $c_{y, t}$ is the conditional mean of $y_{t+1} \equiv \theta \ln (\delta)-\frac{\theta}{\psi} g_{t+1}+\theta r_{m, t+1}$, and $\operatorname{var}_{y, t}$ is its conditional variance. Using the conjectured solution, the approximation for the return, the process for the state variables, and (4), it follows that the conditional mean $c_{y, t}$ (suppressing all constants) is,

$$
-\left[\frac{\theta}{\psi} x_{t}\right]+\theta\left\{\left[\kappa_{1}\left(A_{1} \rho x_{t}+A_{2} \nu_{1} \sigma_{g, t}^{2}\right)\right]-A_{1} x_{t}-A_{2} \sigma_{g, t}^{2}+x_{t}\right\}
$$

and the conditional variance $\operatorname{var}_{y, t}$

$$
\operatorname{var}_{t}\left[-\frac{\theta}{\psi} \eta_{t+1}+\theta\left(\eta_{z, t+1}+\eta_{t+1}\right)\right]=\operatorname{var}_{t}\left[-\frac{\theta}{\psi} \eta_{t+1}+\theta A_{1} \kappa_{1}(\rho-\omega) \eta_{t+1}+\theta A_{2} w_{t+1}+\theta \eta_{t+1}\right]
$$

where $\eta_{z, t+1}$ is the innovation in $z_{t+1}$, hence,

$$
\operatorname{var}_{y, t}=\left[\theta-\frac{\theta}{\psi}+\theta A_{1} \kappa_{1}(\rho-\omega)\right]^{2} \sigma_{g, t}^{2}+\theta^{2} A_{2}^{2} \sigma_{w}^{2}
$$

Since $c_{y, t}+\operatorname{var}_{y, t} / 2$ must equal zero for all realizations of the state variables, the coefficients $A$ can be solved for by matching the coefficients on the state variables. Collecting all terms in asset pricing condition that involve $x_{t}$, we can derive a solution for $A_{1}$,

It immediately follows that,

$$
-\frac{\theta}{\psi} x_{t}+\theta\left[\kappa_{1} A_{1} \rho x_{t}-A_{1} x_{t}+x_{t}\right]=0 .
$$

$$
A_{1}=\frac{1-\frac{1}{\psi}}{1-\kappa_{1} \rho}
$$

which is (13) in the main text.

Collecting all the $\sigma_{g, t}^{2}$ terms, the solution coefficient for for $\sigma_{g, t}^{2}$, that is $A_{2}$, satisfies

$$
\theta\left[\kappa_{1} \nu_{1} A_{2} \sigma_{g, t}^{2}-A_{2} \sigma_{g, t}^{2}\right]+\frac{1}{2}\left[\theta-\frac{\theta}{\psi}+\theta A_{1} \kappa_{1}(\rho-\omega)\right]^{2} \sigma_{g, t}^{2}=0
$$


which implies that

the solution given in (14).

$$
A_{2}=\frac{0.5\left[\theta-\frac{\theta}{\psi}+\theta A_{1} \kappa_{1}(\rho-\omega)\right]^{2}}{\theta\left(1-\kappa_{1} \nu_{1}\right)}
$$

Given the solution above for $z_{t}$ it is possible to derive the return $r_{a}$ as a function of the evolution of the state variables and the parameters of the model. Suppressing all the constant terms,

$$
r_{a, t+1}=g_{t+1}+\kappa_{1} A_{1} x_{t+1}-A_{1} x_{t}+\kappa_{1} A_{2} \sigma_{g, t+1}^{2}-A_{2} \sigma_{g, t}^{2},
$$

and the one step ahead conditional innovation in the return $r_{a, t+1}$ is,

$$
r_{a, t+1}-E_{t}\left[r_{a, t+1}\right]=B \eta_{t+1}+A_{2} \kappa_{1} w_{t+1},
$$

where $\left.B=\left(1+A_{1} \kappa_{1}(\rho-\omega)\right]\right)$.

Now substituting for $r_{a, t+1}$ and the dynamics of $g_{t+1}$ we can re-write the IMRS in terms of the state variables - referring to this as the pricing kernel. Suppressing all the constants in the pricing kernel,

$$
\begin{aligned}
m_{t+1} \equiv \ln M_{t+1} & =\theta \ln \delta-\frac{\theta}{\psi} g_{t+1}+(\theta-1) r_{a, t+1} \\
E_{t}\left[m_{t+1}\right] & =-\frac{x_{t}}{\psi}+A_{2}\left(\kappa_{1} \nu_{1}-1\right)(\theta-1) \sigma_{g, t}^{2} \\
m_{t+1}-E_{t}\left(m_{t+1}\right) & \left.=\left\{-\frac{\theta}{\psi}+(\theta-1)\left(A_{1} \kappa_{1}(\rho-\omega)+1\right)\right\} \eta_{t+1}+(\theta-1) A_{2} \kappa_{1} w_{t+1}\right\} \\
& =B_{p k} \eta_{t+1}+(\theta-1) A_{2} \kappa_{1} w_{t+1}
\end{aligned}
$$

where $B_{p k} \equiv\left\{-\frac{\theta}{\psi}+(\theta-1)\left(A_{1} \kappa_{1}(\rho-\omega)+1\right)\right\}=\left[-\frac{\theta}{\psi}+(\theta-1) B\right]$, where recall that $\left.B=\left(1+A_{1} \kappa_{1}(\rho-\omega)\right]\right)$. The innovation in a given return and the innovation in $m_{t+1}$ are critical for determining the risk premium. The risk premium for the aggregate consumption portfolio $r_{a, t+1}$ is determined by computing $E_{t}\left(r_{a, t+1}-r_{f, t}\right)=$ $-\operatorname{cov}_{t}\left[m_{t+1}-E_{t}\left(m_{t+1}\right), r_{a, t+1}-E_{t}\left(r_{a, t+1}\right)\right]-0.5 \operatorname{var}_{t}\left(r_{a, t+1}\right)$. Exploiting the innovations in the return $r_{a, t+1}$ and $m_{t+1}$, it follows that,

$$
E_{t}\left[r_{a, t+1}-r_{f, t}\right]=B\left[\left(-B_{p k}\right) \sigma_{g, t}^{2}\right]+\kappa_{1} A_{2}\left[(1-\theta) \kappa_{1} A_{2} \sigma_{w}^{2}\right]-0.5 v a r_{t}\left(r_{a, t+1}\right)
$$

where $\operatorname{var}_{t}\left(r_{a, t+1}\right)=B^{2} \sigma_{g, t}^{2}+\left(\kappa_{1} A_{2}\right)^{2} \sigma_{w}^{2}$. Hence in this case $B$ is the $\beta$ of the asset with respect to the growth innovation and $(1-\theta) \kappa_{1} A_{2}$ is the $\beta$ with respect to the volatility shock. The terms in the brackets are the systematic risk-premia for the two common sources of risks in the economy.

The unconditional variance of $r_{a}$ equals:

$$
\operatorname{Var}\left(r_{a, t+1}\right)=\operatorname{Var}\left[\frac{x_{t}}{\psi}+B \eta_{t+1}+A_{2}\left(\kappa_{1} \nu_{1}-1\right) \sigma_{g, t}^{2}+\kappa_{1} A_{2} w_{t+1}\right]
$$

which implies that

$$
\operatorname{Var}\left(r_{a, t+1}\right)=\frac{\operatorname{var}\left(x_{t}\right)}{\psi^{2}}+B^{2} \operatorname{Var}\left(\eta_{t+1}\right)+\left(A_{2}\left(\kappa_{1} \nu_{1}-1\right)\right)^{2} \operatorname{Var}\left(\sigma_{g, t}^{2}\right)+\left(\kappa_{1} A_{2}\right)^{2} \operatorname{Var}\left(w_{t+1}\right)
$$

We can now derive the expression for the risk-free rate and its volatility, as it only depends on the moments of the consumption process and that of $r_{a, t+1}$.

\subsection{The Risk Free Rate and its Volatility}

To derive the risk free rate start with (4) and plug the risk-free rate for $r_{i}$. 


$$
r_{f, t}=-\theta \log (\delta)+\frac{\theta}{\psi} E_{t}\left[g_{t+1}\right]+(1-\theta) E_{t} r_{a, t+1}-\frac{1}{2} \operatorname{Var}_{t}\left[\frac{\theta}{\psi} g_{t+1}+(1-\theta) r_{a, t+1}\right]
$$

subtract $(1-\theta) r_{f, t}$ from both sides and divide by $\theta$, where it is assumed that $\theta \neq 0$. It then follows that,

$$
r_{f, t}=-\log (\delta)+\frac{1}{\psi} E_{t}\left[g_{t+1}\right]+\frac{(1-\theta)}{\theta} E_{t}\left[r_{a, t+1}-r_{t}\right]-\frac{1}{2 \theta} \operatorname{Var}_{t}\left[\frac{\theta}{\psi} g_{t+1}+(1-\theta) r_{a, t+1}\right]
$$

To solve the above expression we need an expression for $\operatorname{Var}_{t}\left[\frac{\theta}{\psi} g_{t+1}+(1-\theta) r_{a, t+1}\right] \equiv \operatorname{Var}_{t}\left(m_{t+1}\right)$.

$$
\operatorname{Var}_{t}\left(m_{t+1}\right)=B_{p k}^{2} \sigma_{g, t}^{2}+(1-\theta)^{2}\left(\kappa_{1} A_{2}\right)^{2} \sigma_{w}^{2}
$$

Further, if the innovation in growth rate process is homoskedastic, the above expression simplifies as $\sigma_{w}^{2}=0$. The unconditional mean of $r_{f, t}$ is derived by substituting the expression for the $r_{a, t+1}$ risk-premium, and (29) into (28). This substitution yields,

$$
E\left(r_{f, t}\right)=-\log (\delta)+\frac{1}{\psi} E(g)+\frac{(1-\theta)}{\theta} E\left[r_{a, t+1}-r_{t}\right]-\frac{1}{2 \theta}\left[B_{p k}^{2} E\left(\sigma_{g, t}^{2}\right)+(1-\theta)^{2}\left(\kappa_{1} A_{2}\right)^{2} \sigma_{w}^{2}\right]
$$

where $B_{p k}$ is defined earlier. Note that $E\left[\sigma_{g, t}^{2}\right]=\operatorname{Var}(\eta)$

The unconditional variance of $r_{f, t}$ is,

$$
\operatorname{Var}\left(r_{f, t}\right)=\left(\frac{1}{\psi}\right)^{2} \operatorname{Var}\left(x_{t}\right)+\left\{\frac{1-\theta}{\theta} K_{2}-B_{p k}^{2} \frac{1}{2 \theta}\right\}^{2} \operatorname{Var}\left(\sigma_{g, t}^{2}\right)
$$

where $K_{2} \equiv\left[\frac{\theta}{\psi} B+(1-\theta) B^{2}\right]-0.5 B^{2}=B\left(-B_{p k}\right)-0.5 B^{2}$. Note that $K_{2}$ determines the time varying portion of the risk-premium on $r_{a, t+1}$. The portion $B\left(-B_{p k}\right)$ is due to the leading term in the risk-premium and the term $-0.5 B^{2}$ is due to the Jensen's inequality effect in the continuous risk premium.

\subsection{Separating Consumption and Dividends}

In this section we augment the above consumption dynamics by a separate dividend process. As the consumption process will be identical to the one presented above, it follows that the solution for $z_{t}$ and therefore $r_{a, t+1}$ and $r_{f, t}$ are completely unaltered. Consequently are focus in this section is solely on the return on the aggregate dividend process which we interpret to the return on the value weighted market portfolio.

The specifics of the consumption-dividend model are as follows:

$$
\begin{aligned}
g_{t+1} & =x_{t}+\eta_{t+1} \\
g_{d, t+1} & =\mu_{d}+\lambda x_{t}+\eta_{d, t+1} \\
\eta_{t+1} & =\sigma_{g, t} \eta_{c, t+1} \\
\eta_{d, t+1} & =\tau \lambda \sigma_{g, t} \eta_{c, t+1}+\sqrt{1-\tau^{2}} \lambda \sigma_{g, t} e_{d, t+1} \\
\eta_{c, t+1}, \eta_{d, t+1} & \sim N(0,1) \quad \text { and } \operatorname{corr}_{t}\left(\eta_{t+1}, \eta_{d, t+1}\right)=\tau
\end{aligned}
$$

where $\eta_{c, t+1}$ and $e_{d, t+1}$ are uncorrelated. Note that this framework ensures that the $g_{t+1}$ process is identical to that discussed earlier in (7), and (9). Moreover, this structure implies that the conditional variance of $\eta_{t+1}$ and $\eta_{d, t+1}$ is $\sigma_{g, t}^{2}$ and $\lambda^{2} \sigma_{g, t}^{2}$ respectively. The relevant state variables for deriving asset prices are $x_{t}$ and $\sigma_{g, t}$. 


\subsubsection{Market Return and its Volatility}

Let the return on the aggregate dividend process be the market return. Then the $z_{i, t}=A_{0, m}+A_{1, m} x_{t}+$ $A_{2, m} \sigma_{t}^{2}$, and the innovation in the market return is

$$
r_{m, t+1}=g_{d, t+1}+\kappa_{1, m} A_{1, m} x_{t+1}-A_{1, m} x_{t}+\kappa_{1, m} A_{2, m} \sigma_{t+1}^{2}-A_{2, m} \sigma_{t}^{2}
$$

The solution for $A_{1, m}=\frac{\lambda-\frac{1}{\psi}}{1-\kappa_{1, m} \rho}$. Further the solution for $A_{2, m}$ can be derived by using the pricing kernel to price $r_{m, t+1}$, that is $E_{t}\left[\exp \left(m_{t+1}+r_{m, t+1}\right)\right]=1$. Collecting all the $x$ terms we find that

$$
-\frac{x}{\psi}+x \kappa_{1, m} A_{1, m} \rho-A_{1, m} x+\lambda x=0,
$$

which implies that

$$
A_{1, m}=\frac{\lambda-\frac{1}{\psi}}{1-\kappa_{1, m} \rho}
$$

It follows that

$$
\begin{aligned}
r_{m, t+1} & =g_{d, t+1}+\kappa_{1} A_{1, m} x_{t+1}-A_{1, m} x_{t}+\kappa_{1, m} A_{2, m} \sigma_{g, t+1}^{2}-A_{2, m} \sigma_{g, t}^{2} \\
r_{m, t+1}-E_{t}\left(r_{m, t+1}\right) & =\tau \lambda \eta_{t+1}+e_{t+1}+\kappa_{1} A_{1, m}(\rho-\omega) \eta_{t+1}+\kappa_{1} A_{2, m} w_{t+1} \\
& =B_{m} \eta_{t+1}+e_{t+1}+\kappa_{1, m} A_{2, m} w_{t+1}
\end{aligned}
$$

where $B_{m}=\left(\tau \lambda+\kappa_{1, m} A_{1, m}(\rho-\omega)\right)$.

We use the following pricing kernel approach to solve for $A_{2, m}$,

$$
\exp \left\{E_{t}\left(m_{t+1}\right)+E_{t}\left(r_{m, t+1}\right)+0.5 \operatorname{Var}_{t}\left(m_{t+1}+r_{m, t+1}\right)\right\}=1
$$

Now note that

$$
\begin{aligned}
\operatorname{Var}_{t}\left(m_{t+1}+r_{m, t+1}\right) & =\operatorname{Var}_{t}\left[B_{p k} \eta_{t+1}+(\theta-1) A_{2} \kappa_{1} w_{t+1}+B_{m} \eta_{t+1}+e_{t+1}+\kappa_{1} A_{2, m} w_{t+1}\right] \\
& =\left[B_{p k}+B_{m}\right]^{2} \sigma_{g, t}^{2}+\left(1-\tau^{2}\right) \lambda^{2} \sigma_{g, t}^{2}+\left[(\theta-1) \kappa_{1} A_{2}+\kappa_{1} A_{2, m}\right]^{2} \operatorname{Var}\left(w_{t+1}\right) \\
& =\left\{\left[B_{p k}+B_{m}\right]^{2}+\left(1-\tau^{2}\right) \lambda^{2}\right\} \sigma_{g, t}^{2}+\left[(\theta-1) \kappa_{1} A_{2}+\kappa_{1} A_{2, m}\right]^{2} \sigma_{w}^{2}
\end{aligned}
$$

where $B_{m, d} \equiv\left[B_{p k}+B_{m}\right]$, will as we will see the $\beta$ of the asset.

Collect now all the $\sigma_{g, t}^{2}$ terms,

$$
\begin{gathered}
(\theta-1) A_{2}\left(\kappa_{1} \nu_{1}-1\right)+A_{2, m}\left(\kappa_{1, m} \nu_{1}-1\right)+\frac{B_{m, d}^{2}+\left(1-\tau^{2}\right) \lambda^{2}}{2}=0 \\
A_{2, m}=\frac{(1-\theta) A_{2}\left(1-\kappa_{1} \nu_{1}\right)+0.5\left(B_{m, d}^{2}+\left(1-\tau^{2}\right) \lambda^{2}\right)}{\left(1-\kappa_{1, m} \nu_{1}\right)}
\end{gathered}
$$

Deriving the Equity Premium on $r_{m, t+1}$,

$$
\begin{aligned}
r_{m, t+1}-E\left(r_{m, t+1}\right) & =-\frac{x_{t}}{\psi}+B_{m} \eta_{t+1}+e_{t+1}+\kappa_{1} A_{1, m}(\rho-\omega) \eta_{t+1}+A_{2, m}\left(\nu_{1} \kappa_{1, m}-1\right) \sigma_{g, t}^{2}+A_{2, m} \kappa_{1, m} w_{t+1} \\
& =-\frac{x_{t}}{\psi}+\left(\kappa_{1} A_{1, m}(\rho-\omega)+\tau\right) \eta_{t+1}+e_{t+1}+A_{2, m}\left(\nu_{1} \kappa_{1}-1\right) \sigma_{g, t}^{2}+A_{2, m} \kappa_{1} w_{t+1}
\end{aligned}
$$


Hence,

$$
\operatorname{Var}\left(r_{m}\right)=\frac{\sigma_{x}^{2}}{\psi^{2}}+B_{m}^{2} \sigma_{\eta}^{2}+\left(1-\tau^{2}\right) \lambda^{2} \operatorname{Var}(\eta)+\left[A_{2, m}\left(\nu_{1} \kappa_{1}-1\right)\right]^{2} \operatorname{Var}\left(\sigma_{g_{t}}^{2}\right)+\left(A_{2, m} \kappa_{1}\right)^{2} \sigma_{w}^{2}
$$

Recall, that the $\operatorname{Var}\left(e_{t+1}\right)=\left(1-\tau^{2}\right) \lambda^{2} \operatorname{Var}\left(\eta_{t+1}\right)$. The equity premium is derived based on $E_{t}\left(r_{m, t+1}-\right.$ $\left.r_{f, t+1}\right)=-\operatorname{cov}_{t}\left(m_{t+1}-E_{t}\left(m_{t+1}\right), r_{m, t+1}-E_{t} r_{m, t+1}\right)-0.5 \operatorname{Var}_{t}\left(r_{m, t+1}\right)$. Thus,

$$
E_{t}\left(r_{m, t+1}-r_{f, t}\right)=B_{m}\left[\left(-B_{p k}\right) \sigma_{g, t}^{2}\right]+A_{2, m} \kappa_{1, m}\left[(1-\theta) A_{2} \kappa_{1} \sigma_{w}^{2}\right]-0.5 \operatorname{Var}_{t}\left(r_{m, t+1}\right)
$$

where, $0.5 \operatorname{Var}_{t}\left(r_{m, t+1}\right)=0.5\left\{B_{m}^{2} \sigma_{g, t}^{2}+\left(1-\tau^{2}\right) \lambda^{2} \sigma_{g, t}^{2}+\left(A_{2, m} \kappa_{1, m}\right)^{2} \sigma_{w}^{2}\right\}$. Note that in the premium formulas $\kappa_{1}$ will always show up from the pricing kernel and the second $\kappa_{*}$ is coming from the asset under consideration. The unconditional variance of the $z_{d, t}$-the market price-dividend ratio is

$$
\operatorname{Var}\left(z_{d, t}\right)=A_{1, m}^{2} \operatorname{Var}\left(x_{t}\right)+A_{2, m}^{2} \operatorname{Var}\left(\sigma_{g, t}^{2}\right)
$$

\subsection{Term Structure}

Let the time $t$ price of an $n$ period maturity discount bond be $Q_{t, n}$. Consequently, the holding period return on this bond is $H_{n, t+1}=\frac{Q_{t+1, n-1}}{Q_{t, n}}$, so let the time $t$ price of an $n$ period maturity discount bond be $Q_{t, n}$. Consequently, that the corresponding continuous return is $h_{t, n}=q_{t+1, n-1}-q_{t, n}$, where lower case refers to logs. As before, let $q_{t, n}=D_{0, n}+D_{1, n} x_{t}+D_{2, n} \sigma_{g, t}^{2}$. The solution for $D_{1, n}$ follows from exploiting (32) replacing $r_{m}$ with $h_{n}$. The difference equation that arise is,

$$
\frac{-x_{t}}{\psi}+D_{1, n-1} \rho x_{t}-D_{1, n} x_{t}=0
$$

which implies that $D_{1, n-1} \rho-\frac{1}{\psi}=D_{n}$. With the initial conditions that $D_{1,0}=0$, the solution for $D_{1, n}=-\frac{1}{\psi} \sum_{j=0}^{n-1} \rho^{j}$ for all $n \geq 1$ that is $D_{1, n}=-\frac{1}{\psi}\left[\frac{1}{1-\rho}\left(1-\rho^{n}\right)\right]$. Note that $D_{1, n}$ is the bond analog of $A_{1, m}$.

In a similar fashion the solution for $D_{2, n}$, follows from

$$
(\theta-1) A_{2}\left(\kappa_{1} \nu_{1}-1\right)+\left[D_{2, n-1} \nu_{1}-D_{2, n}\right]+0.5 B_{m, b(n)}^{2}=0
$$

Thus

$$
D_{2, n}=(\theta-1) A_{2}\left(\kappa_{1} \nu_{1}-1\right)+D_{2, n-1} \nu_{1}+0.5 B_{m, b(n)}^{2}
$$

where $D_{2,0}=0$, and $B_{m, b(n)}=\left[B_{p k}+D_{1, n-1}(\rho-\omega)\right]$, where this is the analogous term to $B_{m, d}$ above for equity. Also, note that $D_{2, n}$ is the bond analog of $A_{2, m}$ for equities. Further, note that $\kappa_{1, b}=1$ for all discount bonds of all maturities (for example this is not true for a console).

The term premia on the bond follows

$$
E_{t}\left[h_{t+1, n}-r_{f, t}\right]=B_{b(n)}\left[-B_{p k} \sigma_{g, t}^{2}\right]+D_{2, n}\left[(1-\theta) \kappa_{1} A_{2} \sigma_{w}^{2}\right]-0.5 \operatorname{Var}_{t}\left(h_{t+1, n}\right),
$$

where $B_{b(n)}=D_{1, n-1}(\rho-\omega)$. Note that $B_{b(n)}$ is the bond analog of $B_{m}$, that is, it is the $\beta$ of the asset.

To derive the conditional volatility, we first define explicitly the continuous bond return;

$$
\begin{aligned}
h_{t+1, n} & =\left[D_{0, n-1}-D_{0, n}\right]+\left[D_{1, n-1} \rho-D_{1, n}\right] x_{t}+\left[D_{1, n-1}(\rho-\omega)\right] \eta_{t+1} \\
& +\left[D_{2, n-1} \nu_{1}-D_{2, n}\right] \sigma_{g, t}^{2}+D_{2, n-1} w_{t+1}
\end{aligned}
$$


and the conditional variance is,

$$
\operatorname{Var}_{t}\left(h_{t+1, n}\right)=\left[D_{1, n-1}(\rho-\omega)\right]^{2} \sigma_{g, t}^{2}+D_{2, n-1}^{2} \sigma_{w}^{2}
$$

and the unconditional variance, $\operatorname{Var}\left(h_{t+1, n}\right)$ is

$$
\begin{aligned}
\operatorname{Var}\left(h_{n, t+1}\right) & =\left[D_{1, n-1} \rho-D_{1, n}\right]^{2} \operatorname{Var}\left(x_{t}\right)+\left[D_{1, n-1}(\rho-\omega)\right]^{2} \operatorname{Var}\left(\eta_{t+1}\right) \\
& +\left[D_{2, n-1} \nu_{1}-D_{2, n}\right]^{2} \operatorname{Var}\left(\sigma_{g, t}^{2}\right)+\left(D_{2, n-1}\right)^{2} \sigma_{w}^{2}
\end{aligned}
$$

